\title{
Controlled Surface Wettability by Plasma Polymer Surface Modification
}

\author{
Muzammil Iqbal ${ }^{1, *}$, Duy Khoe Dinh ${ }^{1}$, Qasim Abbas ${ }^{2}$, Muhammad Imran ${ }^{2}$, Harse Sattar ${ }^{2}$ and \\ Aqrab Ul Ahmad ${ }^{2}$ \\ 1 Plasma Engineering Laboratory, Korea Institute of Machinery and Materials, Daejeon 34103, Korea; \\ khoedd@ust.ac.kr \\ 2 School of Physics, Dalian University of Technology, Dalian 116024, China; qsandhu@mail.dlut.edu.cn (Q.A.); \\ imran.physics@yahoo.com (M.I.); harse.sattar@phys.uol.edu.pk (H.S.); \\ aqrabahmad4469@yahoo.com (A.U.A.) \\ * Correspondence: muzammil@kimm.re.kr
}

Received: 10 April 2019; Accepted: 7 May 2019; Published: 9 May 2019

check for updates

\begin{abstract}
Inspired by nature, tunable wettability has attracted a lot of attention in both academia and industry. Various methods of polymer surface tailoring have been studied to control the changes in wetting behavior. Polymers with a precisely controlled wetting behavior in a specific environment are blessed with a wealth of opportunities and potential applications exploitable in biomaterial engineering. Controlled wetting behavior can be obtained by combining surface chemistry and morphology. Plasma assisted polymer surface modification technique has played a significant part to control surface chemistry and morphology, thus improving the surface wetting properties of polymers in many applications. This review focuses on plasma polymerization and investigations regarding surface chemistry, surface wettability and coating kinetics, as well as coating stability. We begin with a brief overview of plasma polymerization; this includes growth mechanisms of plasma polymerization and influence of plasma parameters. Next, surface wettability and theoretical background structures and chemistry of superhydrophobic and superhydrophilic surfaces are discussed. In this review, a summary is made of recent work on tunable wettability by tailoring surface chemistry with physical appearance (i.e. substrate texture). The formation of smart polymer coatings, which adjust their surface wettability according to outside environment, including, $\mathrm{pH}$, light, electric field and temperature, is also discussed. Finally, the applications of tunable wettability and $\mathrm{pH}$ responsiveness of polymer coatings in real life are addressed. This review should be of interest to plasma surface science communality particularly focused controlled wettability of smart polymer surfaces.
\end{abstract}

Keywords: polymer surfaces; surface wettability; plasma surface modification; tunable surface wettability; $\mathrm{pH}$-responsive

\section{Introduction}

Plasma Polymerization has been a vibrant area of research as it offers a versatile route to design materials rationally with tunable functionalities. The exclusive properties of plasma polymer smart coatings like tunable wettability, self-cleaning and antireflective make them prominent in various applications such as biomaterials, drug delivery, adhesion, protective coatings, microelectronic devices, oil-water separation and thin film technology. These smart polymer coatings have attracted considerable interest owing to these remarkable application oriented surface properties, especially surface wettability [1-4]. Smart polymer surfaces with specific wettability are designed by tuning the surface chemistry and the geometric structure [5]. Plasma copolymerization technique of monomers 
with antagonist physicochemical properties is used to optimize chemical composition because of its versatility to obtain specific chemical functionalities [6,7].

In this review, a brief overview of polymers, polymerization techniques, plasma polymerization and surface wettability are discussed. The research background and mechanism of plasma copolymerization and copolymer surface properties, mainly tunable surface wettability, are presented as well.

\section{Plasma Polymerization}

Polymerization is a process to form a polymer by the combination of repeating functional units, called monomers. The wet chemical polymerization techniques such as spin coating and ink-jet printing are widely used as they are low-cost processes. However, the presence of solvent may lead to adverse effects on polymer coatings, such as non-uniform coatings, the impurities by the solvent produces defective coatings that are not suitable for biomaterials and drying processes resulting in inhomogeneous polymer deposition [8,9].

The issues caused by wet chemical polymerization techniques can be overcome via chemical vapor deposition (CVD). The CVD provides uniform coatings in a single dry chemical deposition step. Plasma-enhanced CVD (PECVD), initiated CVD (iCVD) and photoinitiated CVD (piCVD) follow a chain polymerization mechanism, while oxidative CVD (oCVD) follows step-growth polymerization $[10,11]$. All of these CVD techniques for polymerization have a set of advantages and drawbacks limiting these techniques suitable for some particular polymer coatings.

Plasma techniques are employed as plasma etching, plasma grafting and plasma-enhanced CVD. The PECVD is a versatile polymerization method that utilizes precursors in either solid, liquid or gas form for rapid, pinhole free, cross-linked and dry deposition of the polymer. The structural difference between conventional polymer and plasma polymer is shown in Figure 1 [12]. It was found that plasma treatment increases the crosslinking degree in polymer, so its structure compared to the conventional polymer is different.

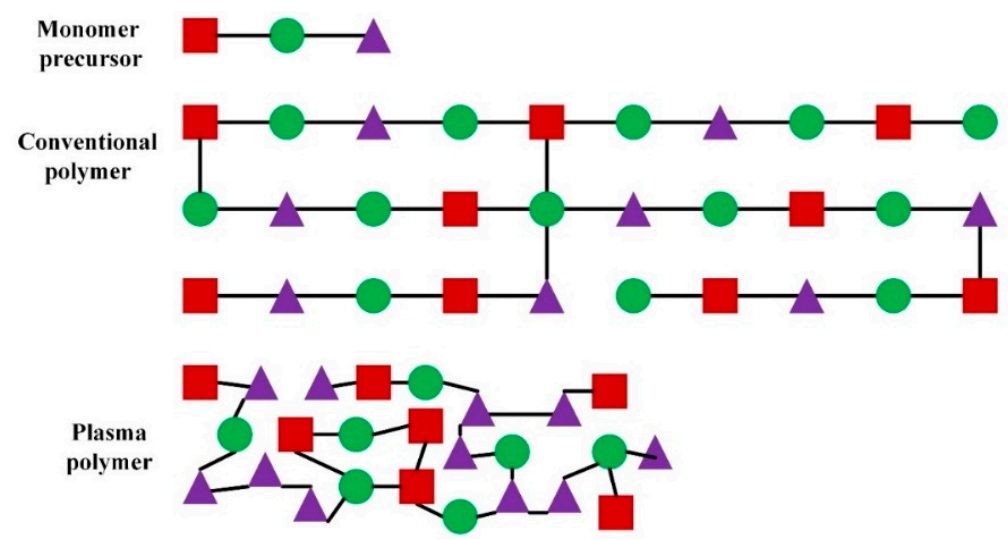

Figure 1. Schematic representations of monomer precursor, conventional polymer and plasma polymer film synthesized from the same monomer precursor.

Plasma polymerization occurs at both low pressure and atmospheric pressure; the purpose of this work is to study low-pressure plasma polymerization. The chain polymerization process occurs with the assistance of plasma energy during plasma polymerization and this plasma energy is used to activate electrons, ions and radicals [13]. In the plasma polymerization process, monomer precursors in vapor form are pumped to the vacuumed plasma reactor. The high-energy excited electrons during glow discharge break molecules into free electrons, ions, radicals and excited molecules. These free radicals and excited molecules condense and polymerize on the substrate, and the ions and electrons crosslink or form chemical bonds with the already deposited polymer, so the properties of plasma polymers are not only determined by precursors but also by the deposition parameters. 
The low-pressure glow discharge plasma characterized as cold plasma can be generated by providing either a continuous current or an alternating current signal to vapors. For continuous ion bombardment, high electron mobility is required that can be achieved by a high-frequency current signal typically in the radio frequency (RF) range. The RF plasma is categorized as cold plasma due to electron energy range from $1 \mathrm{eV}$ to $10 \mathrm{eV}$ [14].

\subsection{RF Plasma Polymerization}

The RF plasma with capacitively-coupled parallel plate configuration is commonly used to induce radicalization of monomer precursor. The plasma power supply usually consists of an RF generator of $13.56 \mathrm{MHz}$ frequency and a matching box to reduce reflected power. The RF power for polymerization process is lower ranging from $10 \mathrm{~W}$ to $400 \mathrm{~W}$. RF-generated plasmas are more stable and have higher-temperature electrons than equivalent $\mathrm{AC}$ or DC, and can be used to process insulating materials, so it is a good choice for polymer deposition from organic monomers. The use of $13.56 \mathrm{MHz}$ is recommended by the international authorities to avoid interference with broadcasting frequencies $[15,16]$.

\subsection{Growth Mechanisms of Plasma Polymerization}

Yasuda [14] proposed bi-cyclic rapid step-growth polymerization mechanisms schematically illustrated in Figure 2. Cycle I consist of activation reaction products from single reactive site species, and cycle II is propagated by divalent reactive species.

\section{Cycle I}

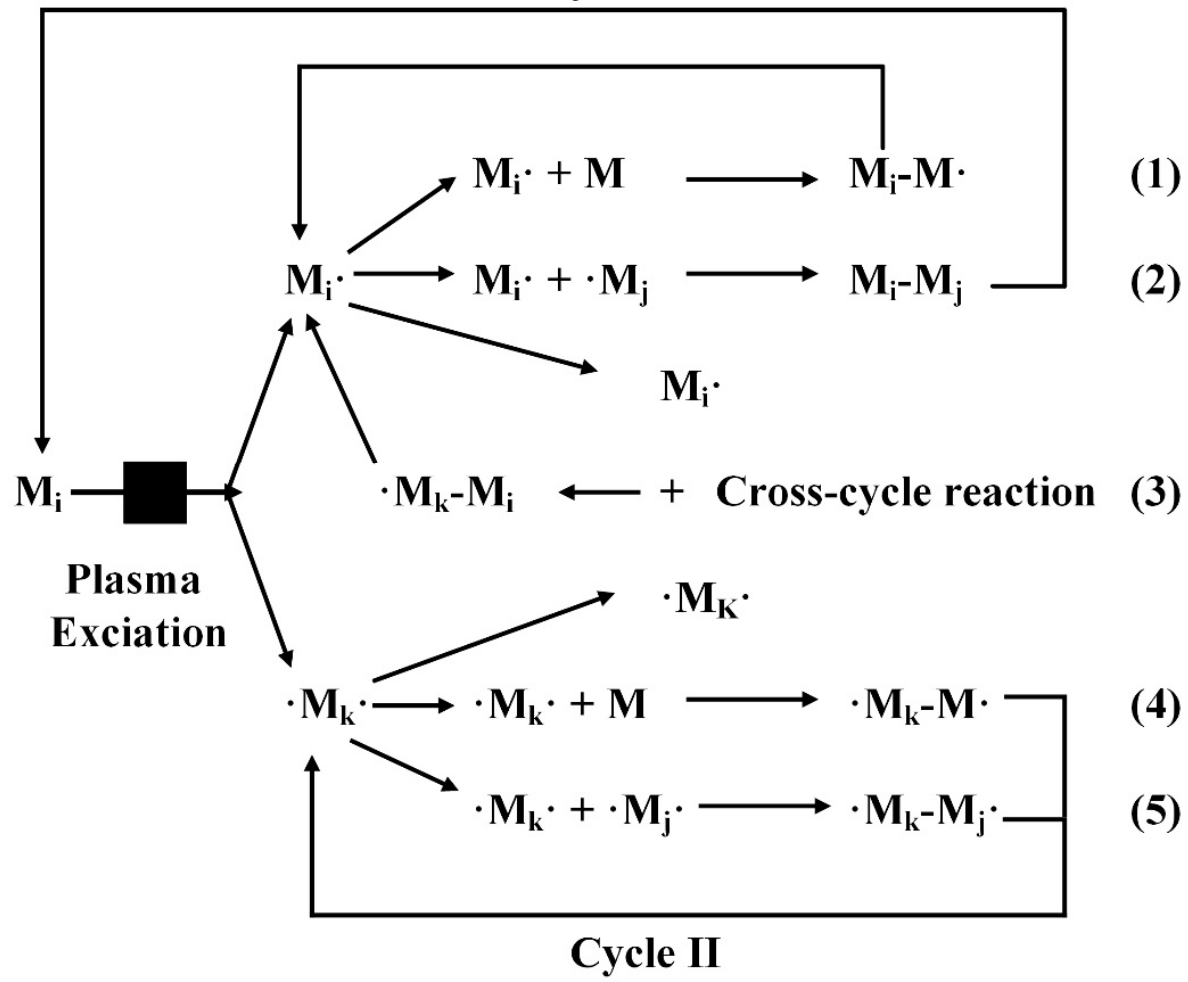

Figure 2. Growth and deposition mechanisms of plasma polymerization.

The reactive species are characterized as free radicals in Figure 2. As the same charge ion cannot react to each other and an equal number of positive and negative charge ions are needed for growth mechanisms. Therefore, the role of the ion in growth mechanisms can be excluded.

The single reactive species or divalent reactive species can be polymerized with monomer by shifting the radical center and leaving it open for more polymerization process. Reaction (5) shows 
divalent reactive species can react with other divalent species to form a new bond while leaving additional reactive sites for further polymerization. Reaction (1), (4) and (5) show the addition of reactive species to the monomer or other reactive species which is same as observed during initiation and propagation reaction in the chain growth free radical polymerization. Reaction (2) shows the formation of the oligomer (combination of few monomer units) by losing its radical center, which is same as the termination reaction in the chain growth free radical polymerization. Moreover, reaction (3) combines single reactive species with divalent reactive species by the cross-cycle reaction and presence of radical center shows the continuity of polymerization reaction. While repeating these steps, the size of the gaseous species increases, and the saturation vapor pressure of the species decreases, which forces the species to be deposited on the substrate in the form of polymer.

\subsection{Influence of Plasma Parameters}

The polymer chemistry and morphology during plasma polymerization can be affected by numerous internal and external factors. The most important external factors are system pressure, monomer flow rate, input power and deposition time [14,17].

System pressure is controlled by vacuum pump-out rate from plasma reactor, gas feed rate into the plasma reactor, deposition/fragmentation rate within the plasma reactor and the change in temperature during plasma polymerization. The mean free path between active species is significant at low pressure, thus, uniform deposition throughout the reactor system can be obtained. Low pressure also increases the glow discharge size rising plasma interaction with the substrate [18-20].

The monomer flow rate determines whether the plasma polymerization is carried out in an energy deficient region or monomer deficient region. At constant RF power, the deposition rate increases linearly with increasing flow rate as long as the reaction system moves from monomer deficient region (having much available energy for monomer activation) to energy deficient region. At this point, a balance exists between available energy for reaction and monomer. The further increase in flow rate decreases the resident time of monomer in plasma, consequently the polymer deposition rate decreases (energy deficient region). The rise in flow rate also increases system pressure. Thus, effects associated with high pressure are also dominated by high flow rate as nonuniformity of deposited polymer surface [18-20].

The deposition rate of plasma polymer coatings increases linearly with an increase in input power (energy deficient region), as long as the energy deficient region changes to monomer deficient region. At this point, the maximum deposition rate is obtained due to balance between available energy for reaction and monomer. The further increases in power results as decrease in deposition rate due to the sputtering effect during the polymer film growth in monomer deficient region. The deposition rate of plasma polymer coatings also increases as plasma exposure time increases. Moreover, the chemistry and morphology of deposited polymer might be changed due to cross-linking and etching process [18-20].

The deposition rate of plasma polymer coatings decreases as the substrate temperature increases. A high degree of monomer fragmentation shows the change in deposition mechanism at high temperature. The cross-linking and branching of the deposited polymer increase due to the fragmentation process [18-20].

\subsection{RF Pulsed Plasma Polymerization}

Plasma polymerization under continuous wave $(\mathrm{CW})$ mode produces complete fragmentation of monomer, thus, random polyrecombination of fragments and atoms leads to irregular polymer structure as previously mentioned in Figure 1. The primary cause of small retained irregular polymer structure is the monomer exposure to high power plasma. To overcome this inevitable disadvantage, low power plasma is used, termed as 'mild plasma conditions', but the power modulation can only be done to a certain limit. However, lowering input power by pulsed wave (PW) plasma polymerization is possible $[12,21]$. 
The pulsed plasma polymerization process is used to modulate power from microseconds to milliseconds; in this way, overall power density can be controlled. This pulsation consists of two periods. During the pulse on-time $\left(t_{\text {pulse-on }}\right)$, polymerization by fragmentation and polyrecombination of monomers occur depending on monomer flow, pressure and the plasma power same as in $\mathrm{CW}$ mode. Alternatively, during pulse off-time ( $\left.t_{\text {pulse-off }}\right)$, the free radicals created during $t_{\text {pulse-on }}$ react with monomer and initiate the polymerization process as illustrated in Figure 3. These radicals, in the absence of ions bombardment and photo-irradiation initiate a purely radical chain chemical reaction. During this period $t_{\text {pulse-off }}$ plasma polymer is chemically very similar to the conventional polymer as shown in Figure 1. Thus, the initiation step occurs during the $t_{\text {pulse-on }}$ and propagation step during $t_{\text {pulse-off }}[22,23]$.

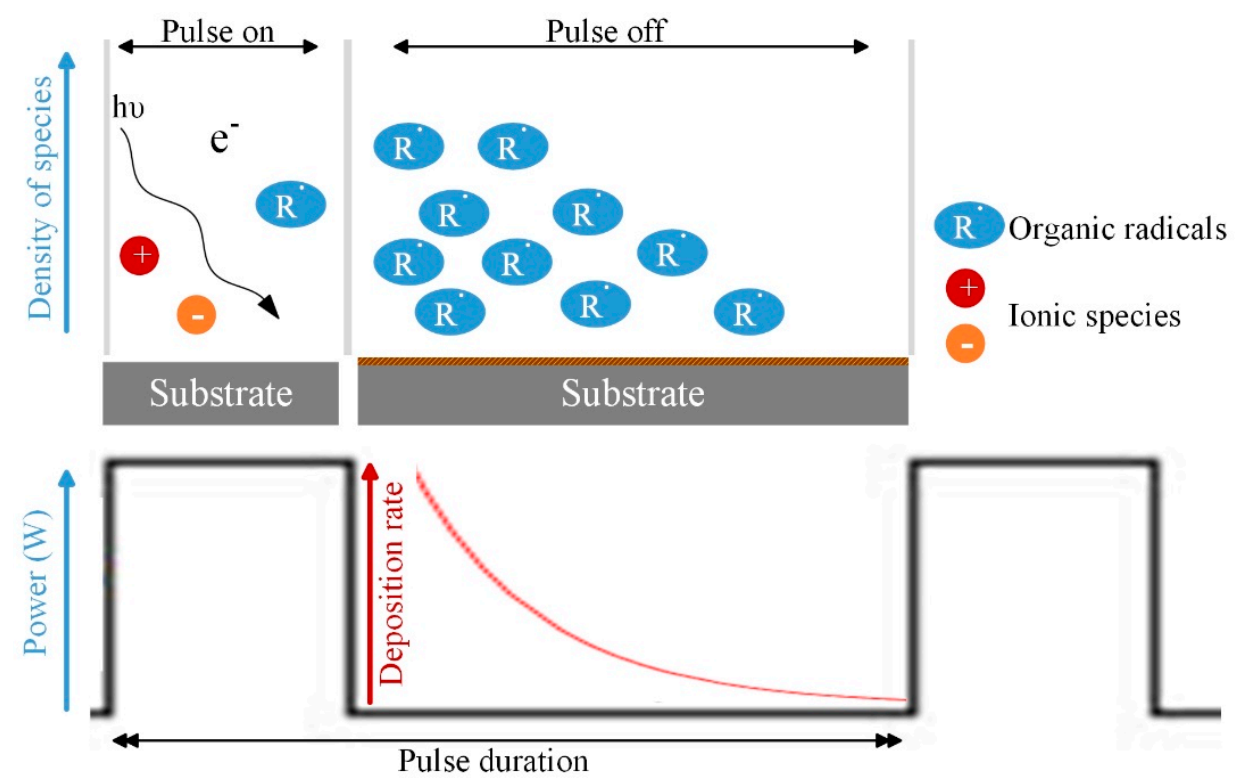

Figure 3. Schematics representation of polymer deposition during pulse-on and pulse-off of pulsed mode plasma polymerization.

The CW and PW plasma polymerization mechanism difference is following (Figure 4):

$$
\begin{array}{lll}
\text { Initiation } & \mathrm{M}+\text { plasma } \rightarrow \mathrm{M}^{\bullet} & \text { PW plasma (during } \text { t }_{\text {pulse-on }} \text { ) } \\
& \mathrm{M}+\text { plasma } \rightarrow \mathrm{A}^{\bullet}+\mathrm{B}^{\bullet}+\mathrm{C}^{\bullet}+\mathrm{D}^{\bullet} & \mathrm{CW} \text { plasma (fragmentation) } \\
\text { Chain growth } & \mathrm{M}^{\bullet}+\mathrm{M} \rightarrow \mathrm{P}^{\bullet} & \text { PW plasma (during t } \text { pulse-off }) \\
& \mathrm{A}^{\bullet}+\mathrm{B}^{\bullet}+\mathrm{C}^{\bullet}+\mathrm{D}^{\bullet} \rightarrow \mathrm{BDCA}+\Delta \mathrm{E} & \mathrm{CW} \text { plasma (polyrecombination) }
\end{array}
$$

The chemical structure and composition of PW plasma polymer coatings depend on the $t_{\text {pulse-on }}$ and $t_{\text {pulse-off }}$ ratio, the so-called duty cycle (DC) and power density:

$$
\mathrm{DC}=\frac{\mathrm{t}_{\text {pulse-on }}}{\mathrm{t}_{\text {pulse-on }}+\mathrm{t}_{\text {pulse-off }}}
$$

A shorter $t_{\text {pulse-on }}$ time and a longer $t_{\text {pulse-off }}$ time favor the conventional structure. In other words, low duty cycle support retention of functional group in PW plasma polymer coatings. The polymer products formed during $\mathrm{T}_{\text {pulse-off }}$ should have a more regular structure as compared to those formed during $\mathrm{T}_{\text {pulse-on }}$. Thus, PW plasma polymer product becomes a mixture of regular and cross-linked chemical structures as shown in Figure 4. The regularity of chemical structure of PW plasma polymer coatings depends on chain growth reaction during $\mathrm{T}_{\text {pulse-off, }}$ duty cycle and pulse frequency. This pulse frequency is different from the RF [22]. 


\subsection{Plasma Copolymerization}

The plasma polymerization has the unique characteristics of being copolymerized almost all the monomers. The properties of copolymers produced from two or more monomers are nearly proportional to the composition of these monomers feed rate in the reactor. Thus, plasma copolymerization is a versatile technique to obtain specific chemical functionalities [24].

Different copolymerization models are developed to explain the radical copolymerization process. If $\mathrm{A}$ and $\mathrm{B}$ are different monomers, the resulting copolymers can be of random $(-\mathrm{AA}-\mathrm{B}-\mathrm{AB}-\mathrm{AAA}-\mathrm{B}-\ldots)$, alternating $(-\mathrm{A}-\mathrm{B}-\mathrm{A}-\mathrm{B}-\ldots)$ or block (-AA-BBB-AAA-BB-) structure $[25,26]$.
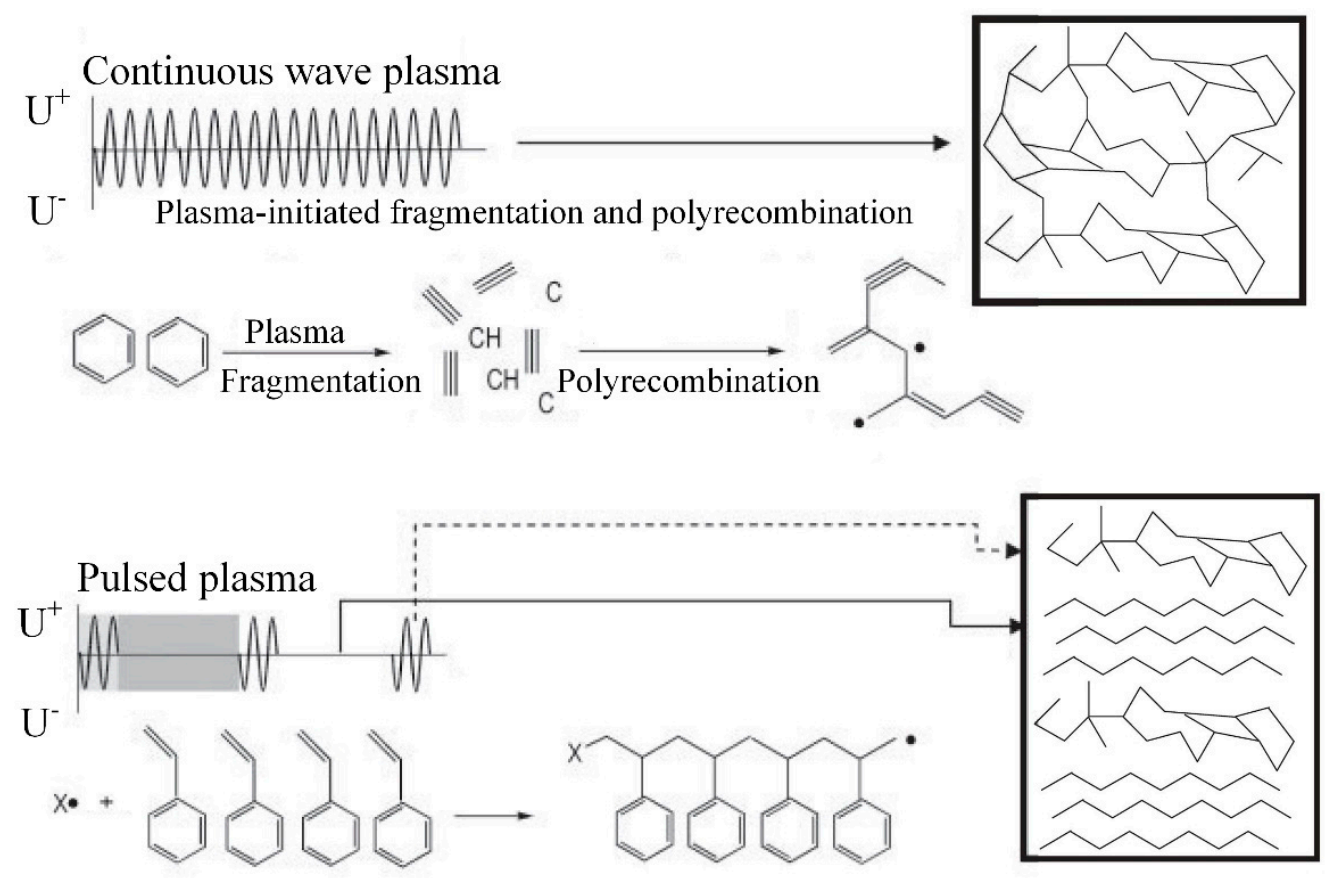

Plasma activation + radical gas-phase polymerization

Figure 4. Schematics of continuous wave (CW) and pulsed wave (PW) mode plasma polymerization and their products [22].

\section{Surface Wettability}

The surface wettability of a solid by the liquid is the most delicate and key aspect of surface science due to its various everyday applications, including printability, anti-fogging, anti-bacterial, anti-reflection, field-effect transistor, self-cleaning windows, cookware coatings, waterproof textiles, corrosion resistance, oil-water separation and anti-bioadhesion [27-29]. The surface wettability is usually governed by the chemical composition and morphology of solid surface. When a liquid drop makes contact with a solid surface, it will either retain its drop like shape or spread out on the solid surface, this property is characterized by using contact angle (CA) measurements. The liquid droplet tends to form an angle with the solid surface when it is placed in contact with the solid surface. This contact angle can be measured between the horizontal line and tangential line of the liquid surface near the liquid-solid-vapour three-phase contact line as shown in Figure 5. According to water CA (WCA) measurements, the surface wettability can be divided into four categories. The surfaces are hydrophobic and hydrophilic with WCA on solid surfaces in the range $90^{\circ}<\theta<150^{\circ}$ and $10^{\circ}<\theta<$ $90^{\circ}$, respectively. The surfaces with WCA greater than $150^{\circ}$ are called superhydrophobic and WCA less than $10^{\circ}$ are called superhydrophilic [30,31]. Superhydrophobic surfaces can be found in nature of lotus leaves, ramie leaves, red rose petals, rice leaves, butterfly's wings, peacock feathers, fish skin and so on [31]. 

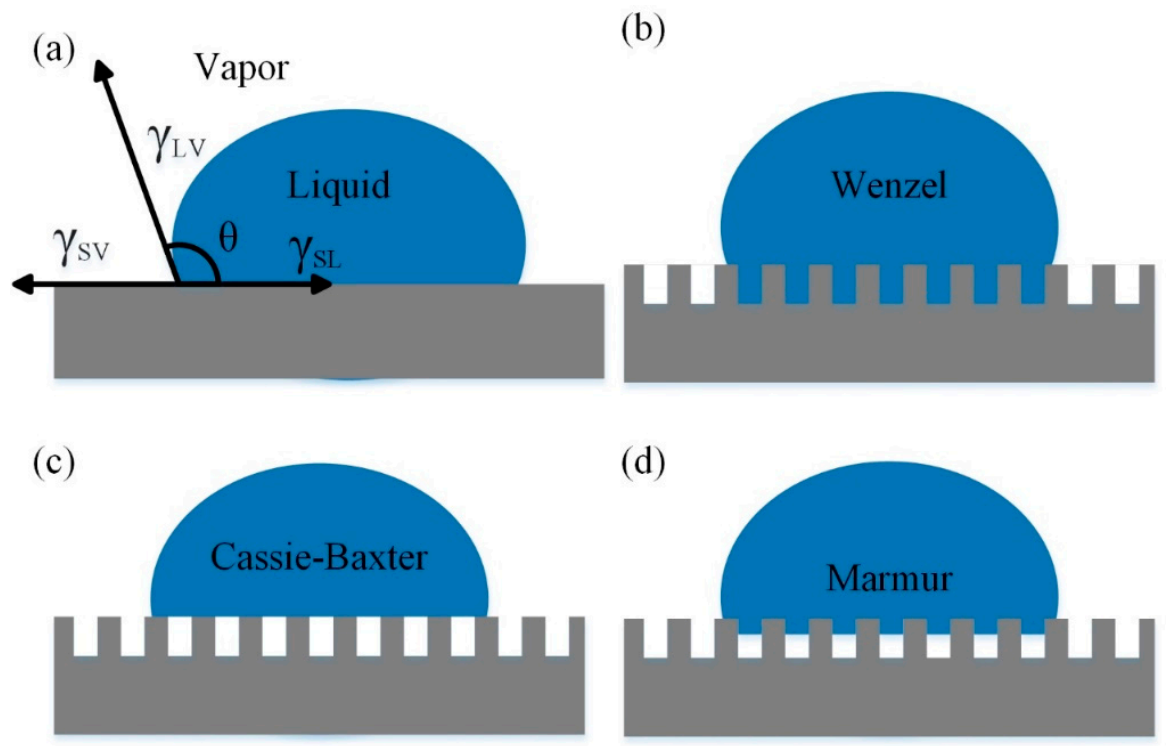

Figure 5. Schematic representation of a water droplet on smooth and rough surfaces (a) Young's equation, (b) Wenzel state, (c) Cassie-Baxter state and (d) Marmur state.

\subsection{Static and Dynamic Wettability}

The droplet contact angle measurements on the solid surface are performed by both statically and dynamically. The CA measurements of a static liquid droplet on a solid surface are known as static contact angle (SCA). Moreover, for dynamic wettability, the sliding angle (SA) or contact angle hysteresis (CA hysteresis) is measured. High SCA reveals that the solid surface repels liquid droplet; moreover, a low CA hysteresis or small SA indicates a liquid droplet has low adhesion to the solid surface and easily slides on the surface [32-34]. The contact angle is measured during droplet size variation, to change droplet size, the liquid volume is added (advancing CA), or removed (receding CA). The series of advancing CAs are measured by simply adding more liquid to the droplet, and the receding CAs are measured by withdrawing a specific volume of liquid. The advancing CA shows favorability level of a solid surface to wet and receding CA shows vice-versa, i.e., favorability to de-wet. The advancing and receding CAs measurements are more reliable as SCA can adopt any value between advancing and receding CAs. The advancing and receding contact angle difference for a contact line moving in an opposite direction at the same velocity is known as CA hysteresis. The larger value of CA hysteresis shows high resistance between wetting and de-wetting states. The CA hysteresis is commonly induced by surface effects, such as roughness, heterogeneity or surface deformation [35].

\subsection{Theoretical Background}

The wettability of flat surface can be predicted by Young's equation using surface energy [36]:

$$
\cos \theta=\frac{\gamma_{S V}-\gamma_{S L}}{\gamma_{L V}}
$$

where $\gamma$ represents the surface energy between the solid-vapor (SV), solid-liquid (SL) and liquid-vapor $(\mathrm{LV})$ interfaces. The $\theta$ in Young's equation is droplet contact angle with the surface. The large contact angle implies high energy $\left(\gamma_{S L}\right)$ interface (not favorable for the liquid-solid interface), whereas smaller contact angle implies low energy interface (convenient liquid-solid interface). The above mentioned equation is only applicable to physically smooth and chemically homogeneous surfaces.

The Wenzel model [37] and Cassie-Boxter model [38] are two renowned theories to explain the wettability behavior of the rough surface. In the Wenzel state, the droplet is in contact with the solid surface completely, and liquid penetrates into cavities as shown in Figure 5b. This model reveals 
that rough solid has a larger surface area as compared to smooth one, thus Equation (2) is modified by Wenzel:

$$
\cos \theta_{r}=r \cos \theta
$$

where $\theta_{\mathrm{r}}$ is the droplet contact angle on a rough surface, $\theta$ is Young's contact angle on a smooth surface with the same material and $r$ is surface roughness obtained by dividing actual area with the flat projected area. For the flat surface, $r$ becomes 1 , and $r>1$ implies surface roughness features. According to Wenzel model, both hydrophobicity and hydrophilicity are amplified by surface roughness. Moreover, the CA hysteresis increases for high surface roughness due to droplet-solid contact and pinning of the droplet during de-wetting.

However, the Wenzel model state is only applicable to the chemically similar solid surface. According to Cassie-Boxter model liquid, the air is trapped in rough surface cavities, thus, the liquid of the droplet cannot penetrate into these cavities as shown in Figure $5 c$, leading to solid-liquid and liquid-air a composite interface:

$$
\cos \theta_{r}=f_{S L} \cos \theta_{1}+f_{L A} \cos \theta_{2}
$$

where $f_{S L}$ and $f_{L A}$ are the areas fractions of liquid droplet in contact with the solid surface and trapped air in the cavities of the rough surface, respectively; $\theta_{1}$ and $\theta_{2}$ are the CAs of droplet with solid surface and air, respectively. For composite interface, the air part of surface can be considered as completely non-wet $\left(\theta_{1}=180^{\circ}\right.$ and $\left.\theta_{2}=\theta\right) f_{S L}+f_{L A}=1$. Thus, Equation (4) can be written as follows:

$$
\cos \theta_{r}=f_{S L}(1+\cos \theta)-1
$$

Marmur introduced a mixed model, according to this model a liquid droplet partially wets the surface and sits on air packets as shown in Figure 5d [39]. This model modified CA expression:

$$
\cos \theta_{r}=r_{f} f_{S L} \cos \theta+f_{S L}-1
$$

It is possible that the Cassie-Baxter state for a given solid surface can transform into Marmur or Wenzel state, surface roughness and surface chemistry plays a significant role in this regard.

\subsection{Textured Surface Wettability}

As mentioned in Wenzel and Cassie-Baxter models, the surface roughness (surface texture) and surface chemistry are the primary factors to determine liquid droplet behavior on a solid surface and texturing a surface with micro or nano-scale architecture is essential to enhance hydrophobicity and hydrophilicity [40-42].

For hydrophobic solid surface, solid-vapor surface energy $\gamma_{S V}$ is less than solid-liquid surface energy $\gamma_{S L}$. Thus, according to Equation (2), the surface energy becomes low due to trapped air below the drop for textured surface of $30 \mu \mathrm{m}$ roughness order. For hydrophilic solid surface, the solid-liquid surface energy $\gamma_{S L}$ is less than solid-vapor energy $\gamma_{S V}$. Thus, the solid-liquid interface follows the roughness of the textured solid surface, which leads the liquid droplet to a Wenzel state [43].

\section{Surface Functionalization of Plasma Polymer Coatings}

Plasma functionalization is the process of surface modification to improve features and properties of polymers by changing the surface chemistry. The plasma functionalization is achieved in a single step without wet chemistry methods, which positively affects its cost, safety and environmental impact. The surface properties of many materials including glass, metals, ceramics, textiles and a broad range of polymers are improved by plasma functionalization [44]. 


\subsection{Surface Processes During Plasma Functionalization}

The highly reactive species (free radicals and electrons) in plasma initiates various physical and chemical processes by contacting with surfaces depending on plasma parameters [45]. For example, the highly reactive species remove surface contaminations to make ultra-clean surface [46]. The free radicals help to break bonds and promote cross-linking of molecules [47]. The substrate is etched and formed micro or nanometer scale roughness by highly reactive species [48]. The short-lived free radicals are deposited on the substrate to promote specific properties depending on the functional group and this deposition of functional groups is the most important process in plasma functionalization [45].

\subsection{Functionalized Plasma Polymer Coatings}

The functionalization of the polymer by plasma treatment has many advantages over wet-chemical treatment, as wet-chemical methods become unacceptable due to environmental and safety consideration. Functional groups like carboxylic acid groups, hydroxyl groups and amine groups produced by plasma treatment are used to chemically functionalized polymer surfaces [49]. Numerous authors reported the functionalization of polymer materials by exposure to various gaseous plasma treatments, such as oxygen plasma, nitrogen plasma, ammonia plasma and fluorine plasma [50-53]. For example, polymer functionalized with oxygen plasma has low surface energy, whereas polymer functionalized with fluorine plasma has low surface energy improving chemical inertness [54,55]. Moreover, argon plasma treatment can increase crosslinking of polymer surfaces [56,57].

Functionalization by depositing thin polymer coatings is a unique process due to its various applications such as adhesion, surface hardening, surface wettability, tribology, contact lens coating, blood compatibility and diffusion barrier [58]. The functionalization by hydrocarbon polymer deposition is widely used due to its outstanding physical properties such as optical refractive index and microhardness. Methane is used to functionalize contact lens materials such as silicone rubber. The $5 \mathrm{~nm}$ plasma polymer coating on silicone rubber reduces its hydrophobicity and surface tackiness [59]. The $\mathrm{C}_{2} \mathrm{H}_{6}$ plasma polymer coatings functionalize the alkali halide (e.g., $\mathrm{KBr}$ and $\mathrm{NaCl}$ ). These coatings show good adherence to substrate and moisture barriers [60]. The hydrophobic materials are obtained by plasma polymerization of fluorine-containing gases. For example, carbon nanotubes are functionalized to make superhydrophobic using tetrafluoroethylene plasma polymer coatings as shown in Figure 6 [61]. The hydrophobic and oleophobic coatings are obtained by plasma polymerization of perfluoro acrylates [62]. The $1 \mathrm{H}, 1 \mathrm{H}, 2 \mathrm{H}, 2 \mathrm{H}$-perfluorooctyl acrylate precursor is used to get superhydrophobic surface by repetitive bursts of CW plasma polymerization. This small time scale plasma deposition leads to the polymeric nanospheres [63].

The organosilicon monomers are used to functionalize various materials due to its excellent optical, electrical, thermal and biomedical properties. For example, hexamethyldisiloxane $\left(\left(\mathrm{CH}_{3}\right)_{3} \mathrm{SiOSi}\left(\mathrm{CH}_{3}\right)_{3}\right)$ is used to functionalize charcoal to make blood-compatible surfaces to reduce blood cells loss through blood contact $[64,65]$. In addition to the applications of plasma functionalized organosilicon polymers in the biomedical field, they have also been used in protective, conductive and moisture sensitive coatings $[66,67]$. The functionalization by incorporating cyano groups in a polymer made it an attractive material in thermal resistance, electrical properties and gas permeation properties due to its high polarity $[68,69]$. The amino groups are used to the functionalize membrane that can bind toxic components found in patient's blood during blood dialysis [70-72]. 
a

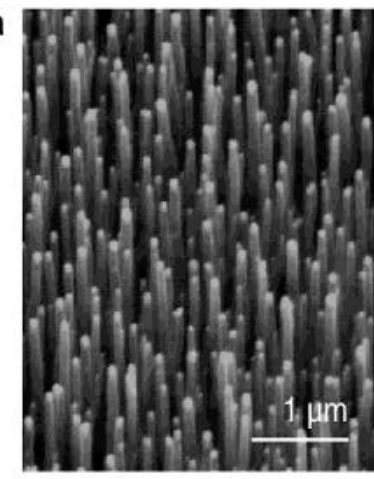

b

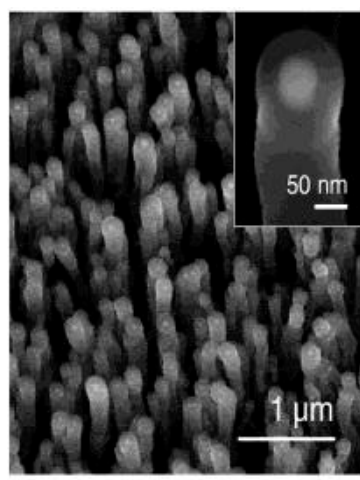

c

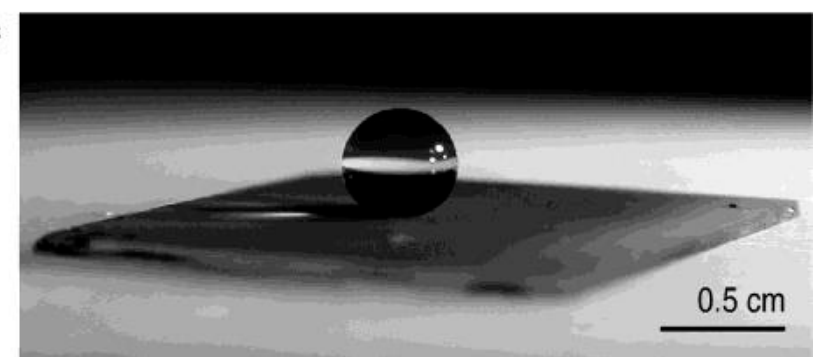

Figure 6. SEM images of carbon nanotube forests. (a) As-grown forest prepared by PECVD, (b) PTFE-coated forest and (c) a spherical droplet suspended on the PTFE-coated forest [61].

\subsection{Functionalized Plasma Copolymer Coatings}

Plasma copolymerization is considered as a promising and versatile technique due to its advantage of the tunable functionality over plasma homopolymerization by adjusting the monomer feed ratio. The combining properties of each monomer that participate in copolymerization opened new doors to tailor a surface [73]. Golub et al. [74] reported one of the early work on RF plasma copolymerization of ethylene (ET) and tetrafluoroethylene (TFE). The rate of ET-co-TFE polymer deposition is exceeded as compared to the calculated deposition rate of homopolymers. The C1s XPS spectra showed that up to $70 \mathrm{~mol} \% \mathrm{TFE}$, the relative amount of carbon to fluorine bonding is of the order $\mathrm{CF}>\mathrm{CF}_{2}>\mathrm{CF}_{3}$. However, this order changed to $\mathrm{CF}_{2}>\mathrm{CF}_{3}>\mathrm{CF}$ for a higher TFE concentration as shown in Figure 7 . The F1s binding energies for the ET-co-TFE polymer coatings linearly increased with the increase of TFE flow rate. Leezenberg et al. [75] deposited plasma copolymer coatings of hexafluoropropylene $\left(\mathrm{C}_{3} \mathrm{~F}_{6}\right)$ and octafluoropropane $\left(\mathrm{C}_{3} \mathrm{~F}_{8}\right)$. They showed the addition of $\mathrm{C}_{3} \mathrm{~F}_{8}$ in plasma polymer coatings increased $\mathrm{CF}_{3}$ groups which reduced surface energy. The SWCA increased with thickness and addition of $\mathrm{C}_{3} \mathrm{~F}_{8}$ due to the lower surface energy of $\mathrm{CF}_{3}$. Jiang et al. [76] utilized plasma copolymerization technique to fabricate hexamethyldisiloxane (HMDSO, $\mathrm{C}_{6} \mathrm{H}_{18} \mathrm{Si}_{2} \mathrm{O}$ ) and octafluorocyclobutane $\left(\mathrm{C}_{4} \mathrm{~F}_{8}\right)$ coatings. They found that with the increases of HMDSO precursor flow the fluorine content decreases and oxygen contents rise.

Beck et al. $[77,78]$ studied plasma copolymerization of acrylic acid with hexane and allylamine. They showed coatings with specific chemical functionality can be produced by controlling the concentration of monomer feed. The higher concentration of carboxylic functional group is achieved by simply increasing the acrylic acid feed rate.

Hirotsu et al. [79] reported pulsed and CW plasma copolymerization of acrylic acid (AA) with hezamethyldisilazane (HMSZ). They found that duty cycle and power have great influence on deposition rate, as deposition rate was greater for pulsed plasma. The deposition rate of the copolymer was higher as compared to HMSZ and AA polymers alone, suggesting copolymerization of AA with HMSZ. The high plasma power with continuous wave favored Si-O functional groups, and low power favored carboxylic functional groups; thus, they tuned water contact angle from hydrophilic to hydrophobic by regulating power. Fahmy et al. [80,81] studied the effect of duty cycle and monomer feed rate of plasma copolymers of acrylic acid and styrene (AA-co-S). They found high deposition 
rate at a high duty cycle and high chain growth polymerization at a low duty cycle of pulsed plasma AA-co-S polymer coatings as shown in Figure 8. Moreover, high retention of the carboxylic group is found at a low duty cycle in both AA and AA-co-S polymer coatings. They also reported the concentration of carboxylic groups increases with the fraction of AA monomer feed rate in copolymer mixture. The deposition rate also increased monastically as AA feed rate rise [80].

Chahine et al. [82] investigated the chemical structure and growth kinetics of pulsed plasma copolymer coatings elaborated from 2-(dimethylamino) ethyl methacrylate (DMAEMA) and $1 \mathrm{H}, 1 \mathrm{H}, 2 \mathrm{H}$-perfluoro-1-decene (HDFD). They claimed that deposition rate per pulse increases up to $30 \mathrm{~W}$ power and then decreases due to the transfer of polymerization from energy deficient region to monomer deficient region. Moreover, the increase of $\mathrm{CF}_{\mathrm{x}}$ and decrease in carboxylic groups are observed from FTIR as HDFD feed rate rise in the mixture of monomers. The reduction in the ratio of the FTIR absorbance bands $\mathrm{A}_{\mathrm{C}=\mathrm{O}} / \mathrm{A}_{\mathrm{OH}}$ and $\mathrm{CF}_{2} / \mathrm{CF}$ are observed for an increase in plasma discharge power; however, these absorbance ratios rise for high pulse off time showing high retention of functional groups at low power.

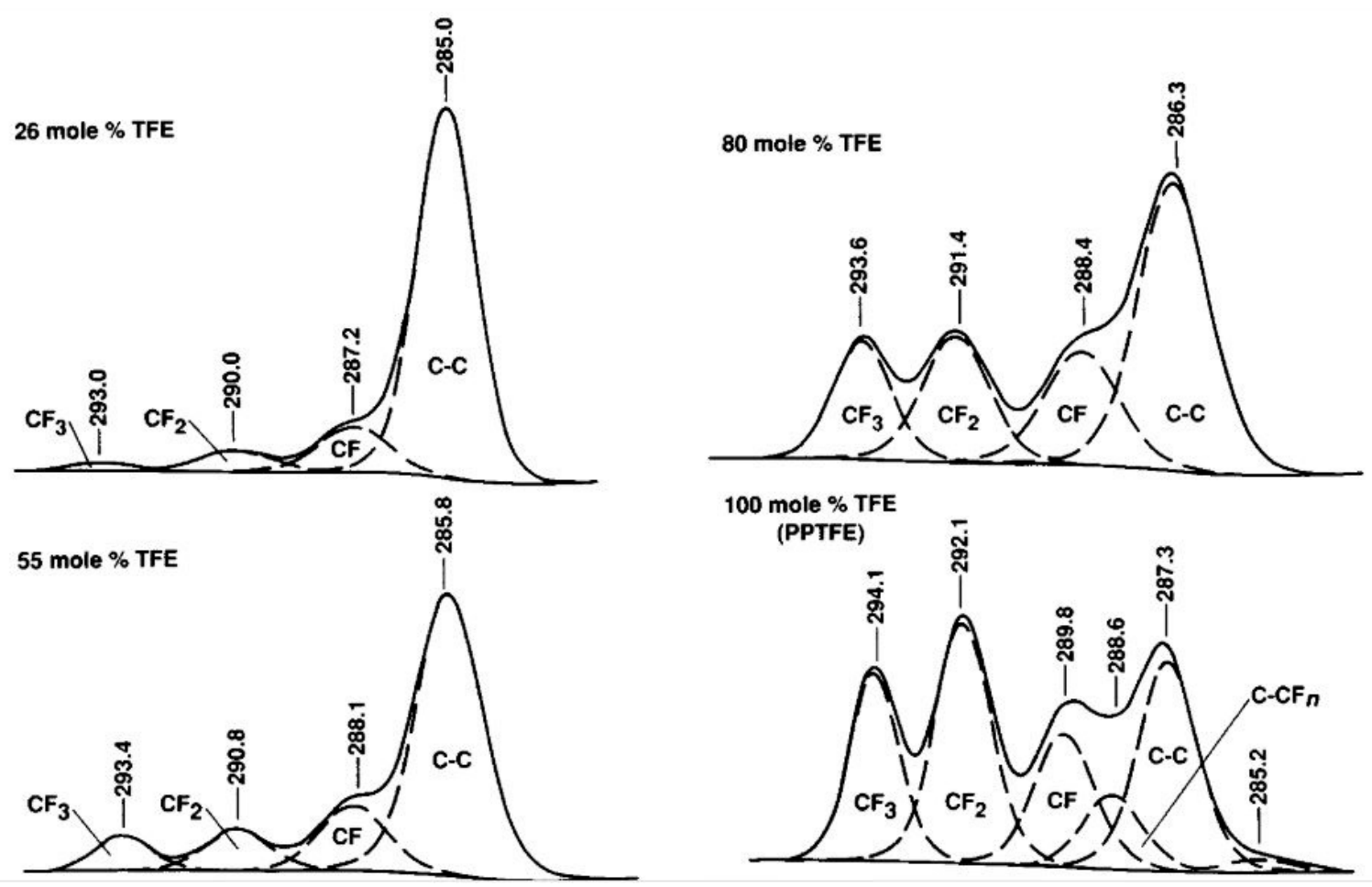

Figure 7. XPS $\mathrm{C} 1_{\mathrm{S}}$ spectra of three ET/TFE plasma copolymers, obtained from 26,55 and $80 \mathrm{~mol} \% \mathrm{TFE}$ in the feeds, and of PPTFE [74]. 

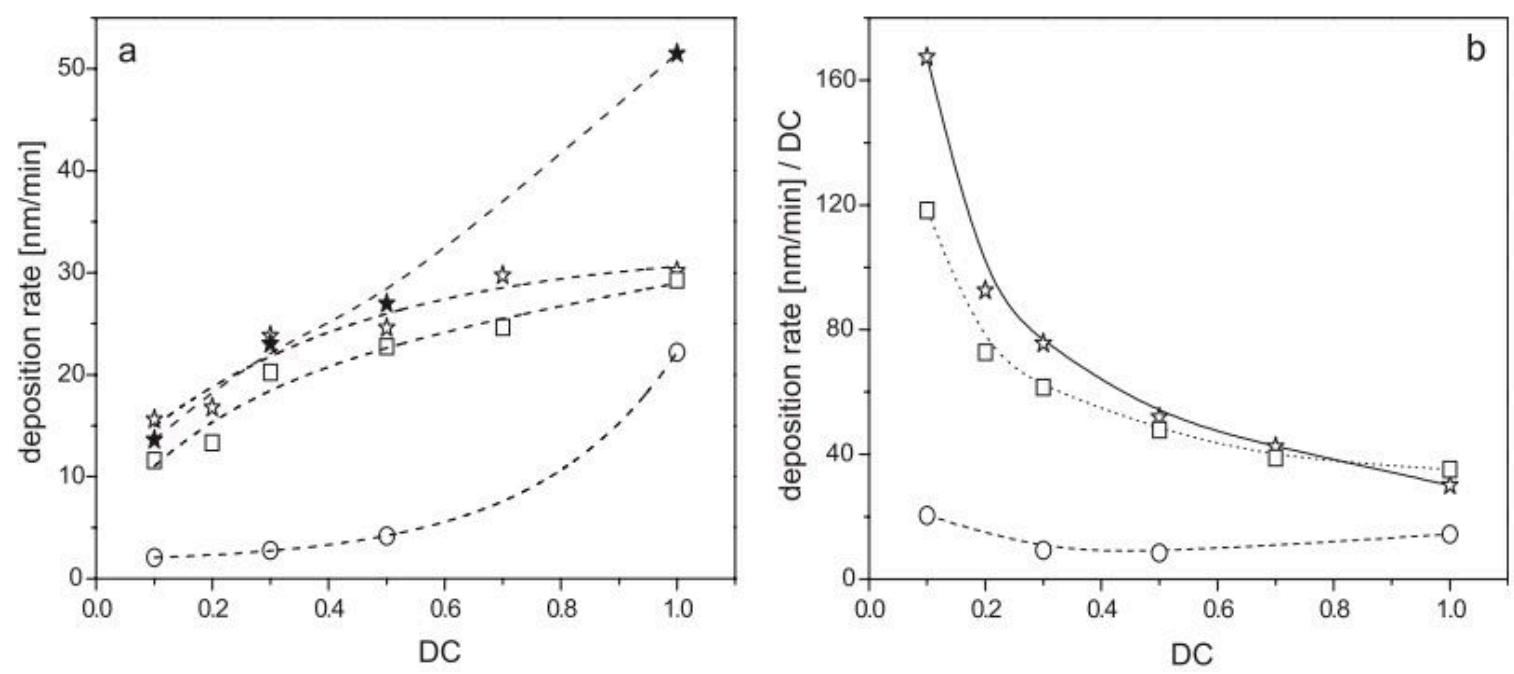

Figure 8. (a) Deposition rates as a function of duty cycle (DC): PAA (square), PS (circle), AA-co-PS polymer calculated (solid star); and AA-co-PS polymer (star). (b) Normalized deposition rate as a function of DC [80].

\section{Surface Wettability of Functionalized Polymer Coatings}

As mentioned earlier, the surface wettability is governed by surface chemistry and enhanced by surface roughness, thus, rough and smooth solid surfaces are designed with different hydrophobic and hydrophilic coatings to exhibit specific surface wettability.

\subsection{Hydrophobic Polymer Coatings}

The hydrophobicity of a flat surface can be increased either by low surface energy coating (changing surface chemistry) or by adding roughness. The maximum SCA that can be achieved for flat surface by using low surface energy coating is $120^{\circ}$ and SCA higher than $120^{\circ}$ can only be obtained by the hydrophobic surface roughness [83].

The fluorocarbon polymer coatings are of particular interest for hydrophobic surfaces due to the extremely low surface energy of fluorine containing $\left(\mathrm{CF}_{2}\right.$ and $\left.\mathrm{CF}_{3}\right)$ functional groups [84]. Most of the fluorocarbon polymer coatings are deposited by $\mathrm{RF}$ plasma polymerization process using either $\mathrm{CW}$ or PW mode [85]. The $\mathrm{CH}_{2} \mathrm{~F}_{2}, \mathrm{CHF}_{3}, \mathrm{C}_{3} \mathrm{~F}_{6} \mathrm{OCF}_{4}, \mathrm{C}_{2} \mathrm{~F}_{6}, \mathrm{C}_{3} \mathrm{~F}_{8}, \mathrm{C}_{4} \mathrm{~F}_{10}$ and $\mathrm{C}_{4} \mathrm{~F}_{8}$ are commonly used precursors for fluorocarbon coating. The hydrophobicity of fluorocarbon coatings depends on the surface chemistry of deposited polymer controlled by precursor feed rate and plasma parameters such as input power, reactor pressure, reactor geometry and plasma operational mode ( $C W$ or PW) $[23,86]$. The fluorocarbons precursors are commonly classified into polymer forming and non-polymer forming by their $\mathrm{F} / \mathrm{C}$ ratios. The fluorocarbon with lower $\mathrm{F} / \mathrm{C}$ ratios is called polymer forming such as $\mathrm{C}_{4} \mathrm{~F}_{8}$ and $\mathrm{C}_{4} \mathrm{~F}_{10}$. Fluorocarbon with high $\mathrm{F} / \mathrm{C}$ ratios is not polymerized such as $\mathrm{CF}_{4}$, and $\mathrm{C}_{2} \mathrm{~F}_{6}$, because $\mathrm{F}$ atoms act as etching agents for hydrocarbon polymer and silicon. Therefore, the $\mathrm{F} / \mathrm{C}$ ratios play a critical role to determine either process leading to etching or polymer deposition and $\mathrm{C}_{3} \mathrm{~F}_{8}$ stands between these two classes. Yasuda et al. [86] considered fluorocarbon plasma polymerization is more complicated as compared to hydrocarbons, due to competition between plasma polymerization and etching. They also suggested that only unsaturated and cyclic fluorocarbon precursors could be used for polymerization. Jihye et al. [87] deposited fluorocarbon polymer coatings using different precursors such as $\mathrm{C}_{2} \mathrm{~F}_{6}, \mathrm{C}_{3} \mathrm{~F}_{8}$ and $\mathrm{C}_{4} \mathrm{~F}_{8}$ on $\mathrm{Si}$ substrate by plasma polymerization process in both $\mathrm{CW}$ and $\mathrm{PW}$ mode. They observed SWCA is higher for $\mathrm{C}_{2} \mathrm{~F}_{6}$ and $\mathrm{C}_{3} \mathrm{~F}_{8}$ polymer coatings by $\mathrm{PW}$ plasma polymerization; however, SWCA of $\mathrm{C}_{4} \mathrm{~F}_{8}$ plasma polymer coating is higher for $\mathrm{CW}$ plasma polymerization as shown in Table 1. 
Table 1. Static water contact angle of fluorocarbon plasma polymer on Si substrate [87].

\begin{tabular}{cccc}
\hline \multicolumn{4}{c}{ Static Water Contact Angle (SWCA) } \\
\hline & $\mathbf{C}_{\mathbf{2}} \mathbf{F}_{\mathbf{6}}$ & $\mathbf{C}_{\mathbf{3}} \mathbf{F}_{\mathbf{8}}$ & $\mathbf{C}_{\mathbf{4}} \mathbf{F}_{\mathbf{8}}$ \\
\hline $\mathrm{PW}(1 \mathrm{kHz})$ & $103.8 \pm 0.2^{\circ}$ & $104.4 \pm 0.5^{\circ}$ & $98.8 \pm 0.3^{\circ}$ \\
$\mathrm{PW}(500 \mathrm{~Hz})$ & $106.0 \pm 1.0^{\circ}$ & $101.5 \pm 0.5^{\circ}$ & $96.0 \pm 0.1^{\circ}$ \\
$\mathrm{PW}(200 \mathrm{~Hz})$ & $74.5 \pm 1.5^{\circ}$ & $78.5 \pm 0.5^{\circ}$ & $81.5 \pm 0.5^{\circ}$ \\
$\mathrm{CW}$ & $102.0 \pm 0.2^{\circ}$ & $101.0 \pm 0.5^{\circ}$ & $112.0 \pm 0.5^{\circ}$ \\
\hline
\end{tabular}

Octafluorocyclobutane $\left(\mathrm{C}_{4} \mathrm{~F}_{8}\right)$ gas belongs to cycloalkanes family and frequently used as hydrophobic coating and etching agent, its chemical structure is shown in Figure 9. The higher SWCA of $\mathrm{C}_{4} \mathrm{~F}_{8}$ for $\mathrm{CW}$ plasma polymerization shows $\mathrm{CW}$ plasma mode favors formation of $\mathrm{CF}_{3}$ and $\mathrm{CF}_{2}$ functional groups and inverse for $\mathrm{C}_{2} \mathrm{~F}_{6}$ and $\mathrm{C}_{3} \mathrm{~F}_{8}$. The $\mathrm{C}_{4} \mathrm{~F}_{8}$ plasma polymer coatings on different smooth substrates exhibit hydrophobic character with small variation depending on the substrate due to highly cross linked $\mathrm{CF}_{3}$ and $\mathrm{CF}_{2}$ groups, and this hydrophobicity is enhanced to superhydrophobicity with SWCA $>160^{\circ}$ and CA hysteresis $<5^{\circ}$ by rough or nanotextured surfaces [88-92]. Labelle et al. [93,94] explained thickness variations of $\mathrm{C}_{4} \mathrm{~F}_{8}$ polymer coatings using $\mathrm{PW}$ and CW plasma. They found that deposition rate is a weak function of input power in CW plasma and for PW plasma thickness rate is significantly low as compared to CW. The deposition rate for PW plasma is attributed almost to $t_{\text {pulse-on, }}$ and there is slight dependence on $t_{\text {pulse-off. Furuya et al. [88] }}$ observed that the chemical structure and chemical bonding of $\mathrm{C}_{4} \mathrm{~F}_{8}$ plasma polymer coating significantly depend on the type of substrate used.

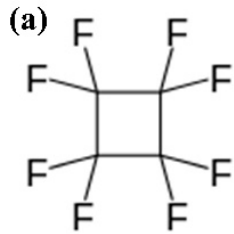

(b)<smiles>C=CC(=O)O</smiles>

Figure 9. The chemical structure of (a) octafluorocyclobutane and (b) acrylic acid.

\subsection{Hydrophilic Polymer Coatings}

The polymers having a polar functional group that make them soluble in the polar solvent (water) are known as hydrophilic polymers [95]. The water solubility of the hydrophilic polymer varies with molecular chain length, molecular crosslinking and polarity of side chain as shown in Table 2. Various methods have been established to produce hydrophilic polymer surface; however, all these methods used a standard approach to introducing new polar functional groups, such as hydroxyl $(\mathrm{OH})$, carboxyl $(\mathrm{COOH})$ and amino groups $\left(\mathrm{NH}_{2}\right)$ to improve surface hydrophilicity [96-98].

Table 2. Polymer structure and water solubility [99].

\begin{tabular}{cc}
\hline Polymer Structural Feature & Water Solubility \\
\hline Chain length increased & Decreases \\
Polar groups ratio increased & Increases \\
Polarity of polar group increased & Increases \\
Cross-linking increased & Decreases \\
\hline
\end{tabular}

The most recent scientific study of the hydrophilic polymers is devoted to the acrylic acid (AA) and its copolymer derivatives [99]. The chemical structure of AA is shown in Figure 9. Allméa et al. [100] observed the hydrophilic behavior of acrylic acid polymer coatings grafted on low and high-density polyethylene, these polymer coatings showed $56^{\circ}$ SWCA on low density polyethylene and $60^{\circ}$ SWCA on high-density polyethylene at room temperature. These polymer coatings show stable wettability 
at room temperature even after a month of storage. However, when these coated samples were heated to $80^{\circ} \mathrm{C}$, they lost their wettability in $1 \mathrm{~h}$, and SWCA increased from $56^{\circ}$ to $87^{\circ}$ for low density polyethylene and from $60^{\circ}$ to $82^{\circ}$ for high-density polyethylene. Moreover, crosslinked polyethylene sample grafted with AA did not lose its polarity and wettability when heated. Gupta et al. [101] observed the $72.9^{\circ}$ SWCA of polyethylene terephthalate (PET) decrease up to $26^{\circ}$ after plasma-induced graft polymerization of acrylic acid depending on the graft density. Sciarratta et al. [102] observed the change in SWCA of polypropylene (PP) from $90^{\circ}$ to $19^{\circ}$ after acrylic acid plasma polymer coatings. Jafari et al. [103] checked surface wettability and water stability of low frequency plasma-deposited AA on polyethylene. They observed $90^{\circ}$ SWCA of polyethylene varied to $10^{\circ}$ after AA plasma polymerization and after water washed the SWCA increases to $60^{\circ}$. The rise in SWCA is due to sharp declines of carboxylic ( $\mathrm{COOH})$ functional group from $28 \%$ to $7 \%$ after being water washed. Voronin et al. [104] checked retention of carboxylic (COOH) functional group of AA pulsed plasma polymer coatings as a function of duty cycle. They found the carboxylic group functionality increases for lower duty cycle. The retention reached to $66 \%$ for $t_{\text {pusle-off }}$ exceeding $5 \mathrm{~ms}$. Moreover, the deposition rate is a strong function of monomer flow rate. Fahmy et al. [105] studied the surface and chemical properties of pulsed plasma polymer coating of AA on glass and aluminum as a function of the duty cycle. They found the deposition rate is nonlinear when it is plotted against duty cycle. Moreover, the carboxylic functional group concentration increases with a lower duty cycle as it favors chain polymerization and high duty cycle support fragmentation.

\subsection{Tunable and $p H$-responsive Surface Wettability}

The surface wettability can be tuned by varying the ratio of hydrophobic/hydrophilic monomers during the preparation of copolymers [99]. The degree of surface wettability also depends on relative cross-linking and polymer functionality as described in Table 2. Peter et al. [106] reported the tunable wetting behavior of micro/nanotextured poly dimethyl siloxane (PDMS). The PDMS substrate is plasma coated with sulfur hexafluoride, fluoroform and octafluorocyclobutane successively. These coatings showed stable superhydrophobicity and superhydrophilicity. Yilgor et al. [107] developed polymeric surface with tunable wettability based on hydrophilic/hydrophobic silica mixture prepared by spin-coating. They have showed gradual change of surface wettability from superhydrophilic to superhydrophobic by tuning hydrophobic silica content in coatings as shown in Figure 10. Chahine et al. [82] studied plasma copolymer having hydrophobic and hydrophilic components. They studied growth kinetics and chemical structure of plasma copolymer elaborated from 2-dimethylamino ethyl methacrylate (DMAEMA) and 1H,1H,2H-perfluoro-1-decene (HDFD) monomers. They observed low peak power and $\mathrm{T}_{\text {pulse-on }}$ lead to better retention of the functional group both in plasma homo- and copolymers and for high peak power and $\mathrm{T}_{\text {pulse-on }}$ fluorinated unit retained better than acrylate in both homopolymers and copolymers. They also found that the presence of HDFD amount give rise to the copolymer growth rate and this growth principally occurs during $\mathrm{T}_{\text {pulse-on }}$. 

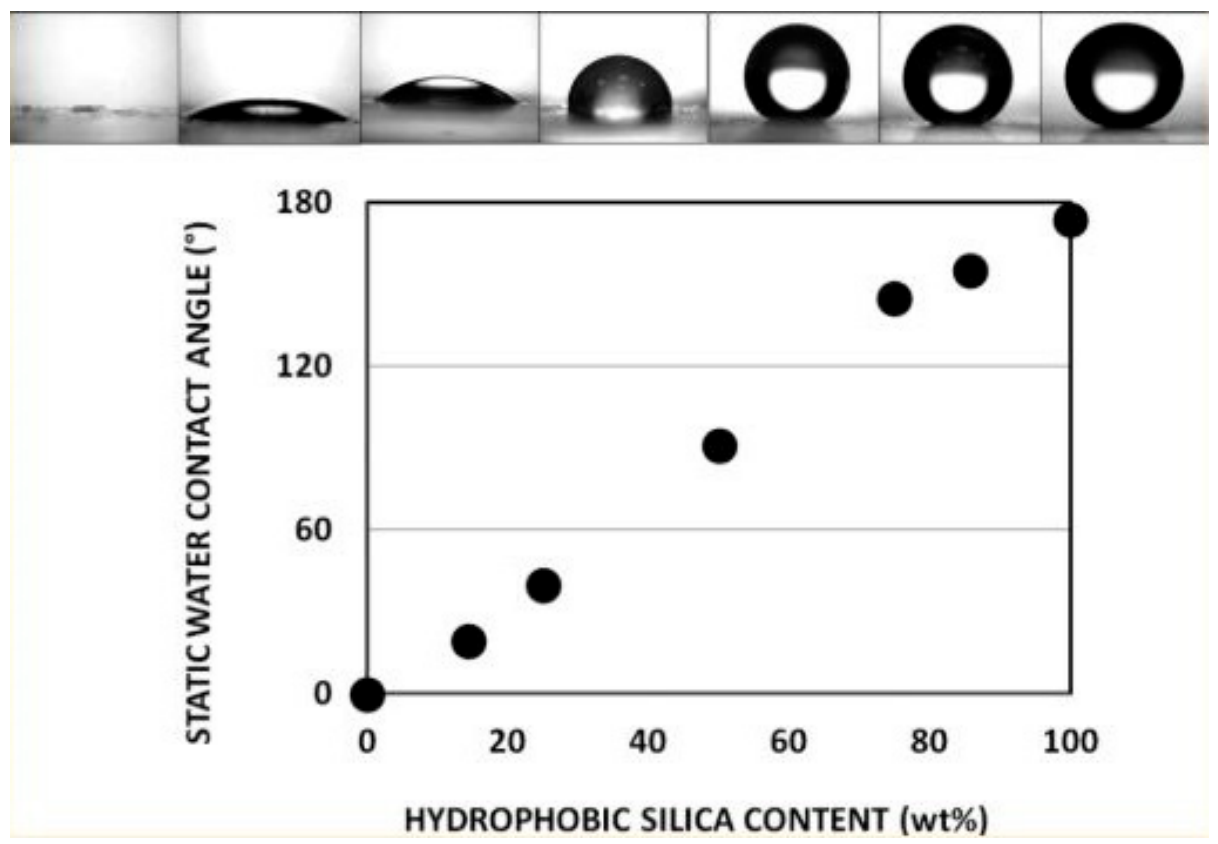

Figure 10. The static water contact angles on silica-coated polystyrene surfaces as a function of the hydrophobic silica content of the coating mixture [107].

Stimuli-responsive polymers undergo a reversible phase transition in response to the external stimuli such as $\mathrm{pH}$, redox, temperature, ultrasound, light, electromagnetic radiation and biomolecules. Different type of stimuli-responsive surfaces are fabricated that reversibly switch to different wetting states [108]. The pH-responsive superwettability is of great importance because of its interesting applications, such as biosensors and drug delivery. Weak polymer bases and acids are commonly used to get a $\mathrm{pH}$-responsive surface with switchable wetting properties [108]. The polymer acids have $\mathrm{pH}$-responsive carboxylic $(\mathrm{COOH})$ group, this carboxylic group at low $\mathrm{pH}$ can be protonated so hydrophobic interaction become dominant, while at high $\mathrm{pH}$, the carboxylic group dissociate into carboxylate anions $\left(\mathrm{COO}^{-}\right)$and become hydrophilic. By the combination of $\mathrm{pH}$-responsive polymer with the rough surface substrate, the switchable wettability can be enhanced [109].

Polyacrylic acid (PAA) is one of the most frequently reported $\mathrm{pH}$-responsive polymer with $\mathrm{pKa}=4.7$ [108]. The PAA chain conformation can change from collapsed state at $\mathrm{pH}<\mathrm{pKa}$ to the stretched state at $\mathrm{pH}>\mathrm{pKa}$ via protonation and deprotonation of carboxylic functional groups. The copolymer coatings containing PAA monomer owing to $\mathrm{pH}$-responsive feature are used to tune responsive surface with switchable wettability. $\mathrm{Xu}$ et al. [110] prepared poly styrene-co-acrylic acid (PS-co-PAA) polymer. They showed SWCA of PS-co-PAA polymer coatings after being dipped in low $\mathrm{pH}$ solution is $73^{\circ}$ and this SWCA value decreases abruptly to a constant value of $43^{\circ}$ as $\mathrm{pH}$ value change to 4 . Zhou et al. [111] fabricated poly 2,2,3,4,4,4-hexafluorobutyl methacrylate-co-polyacrylic acid (PHFBMA-co-PAA)] copolymers with three different segment length on silicon wafers using spin coating technique. They found that PAA ratio in copolymer significantly influences $\mathrm{pH}$-responsive surface wettability; however, all these copolymers show evolutions of SWCA at a similar $\mathrm{pH}$ inflection point at pH 5.25 regardless of PAA concentration. Xia et al. [112] fabricated N-isopropyl acrylamide-co-acrylic acid (NIPAAm-co-PAA) polymer on smooth and rough silicon. They observed reversibly switchable wettability from superhydrophilic to superhydrophobic in response to both narrow temperatures range of about $10^{\circ} \mathrm{C}$ and a relatively wide range of $\mathrm{pH}$ about 10 due to combining effect of the chemical structure variation and the surface roughness. For a flat surface, this dual response switching of NIPAAm-co-PAA polymer is only from hydrophobic to hydrophilic; however, for a rough surface, the extreme change of $150^{\circ}$ in SWCA is observed. 
Muzammil et al. [113,114] fabricated novel and intelligent $\mathrm{C}_{4} \mathrm{~F}_{8}$-co-AA polymers with tunable wettability and $\mathrm{pH}$-responsiveness are demonstrated. A series of plasma $\mathrm{C}_{4} \mathrm{~F}_{8}$-co-AA polymer coatings based on various hydrophilic/hydrophobic monomer feed ratio on the flat and nanotextured low-density polyethylene (LDPE) surfaces are deposited via capacitively coupled RF plasma (CCP). The SWCA of $\mathrm{C}_{4} \mathrm{~F}_{8}$-Co-AA polymer coatings on flat LDPE surfaces tuned from $119^{\circ}$ to $11^{\circ}$, while this surface wetting tunability dramatically enhanced from superhydrophobicity $\left(\mathrm{SWCA}=163^{\circ}\right.$ ) to superhydrophilicity $\left(\mathrm{SWCA}=4^{\circ}\right.$ ) for nanotextured LDPE surfaces (Figure 11). The $\mathrm{C}_{4} \mathrm{~F}_{8}$-co-AA polymer coatings also showed $\mathrm{pH}$-responsive wetting behavior caused by the combined effect of the $\mathrm{pH}$-responsive component (carboxylic acid functional group) and nanotextured surface. The increase of carboxylic acid functional groups in $\mathrm{C}_{4} \mathrm{~F}_{8}$-co-AA polymers shifted the switchable $\mathrm{pH}$-responsive wetting behavior towards low SWCA range. The magnifying effect of the nanotextured surface on $\mathrm{pH}$-responsiveness is also observed.
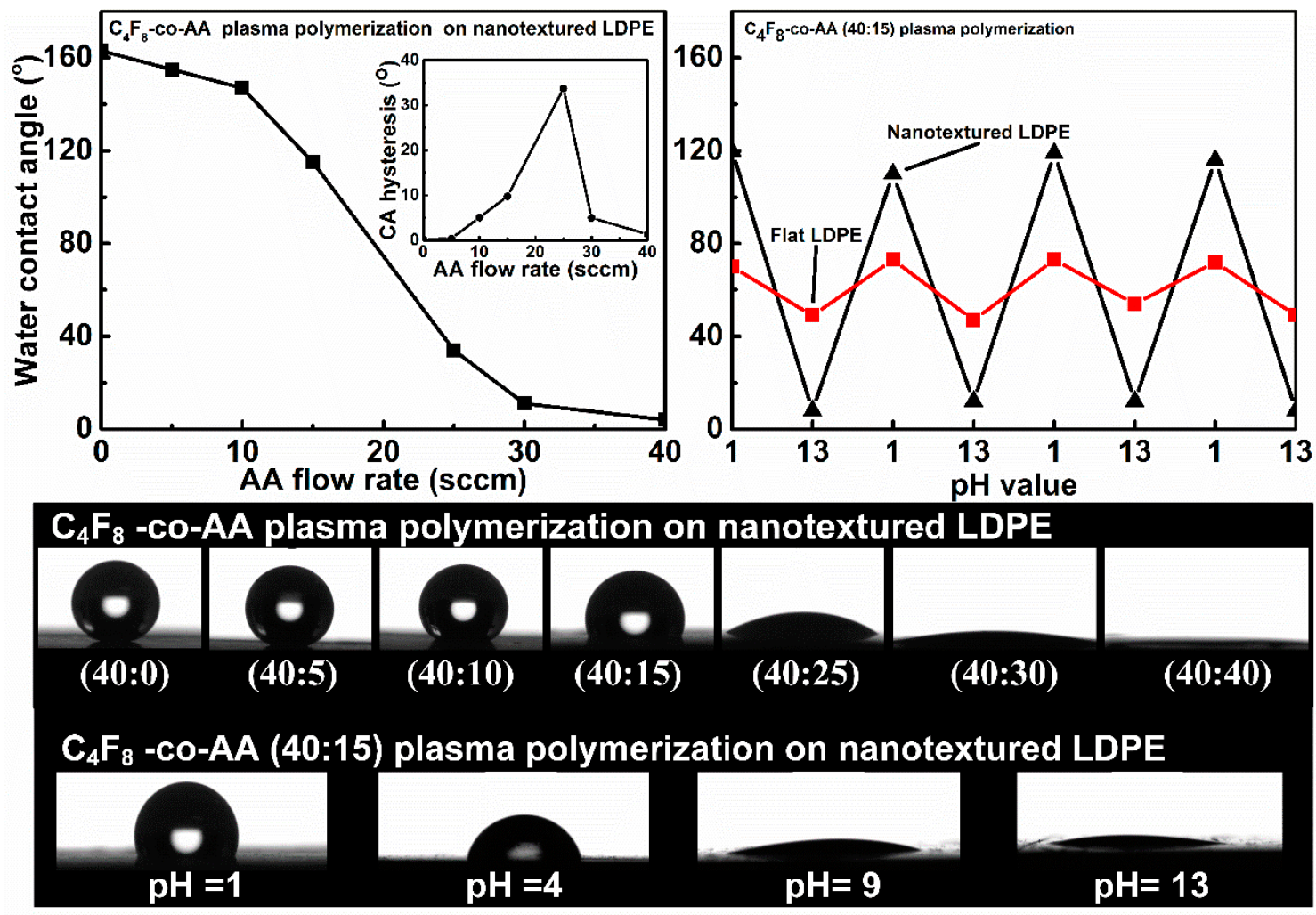

Figure 11. Tunable Wettability and pH-Responsiveness of Plasma Copolymers of Acrylic Acid and Octafluorocyclobutane [113].

The influence of duty cycle in pulsed plasma process with the monomer feed rate on the surface chemistry and wettability of $\mathrm{C}_{4} \mathrm{~F}_{8}$-co-AA polymer coatings is studied. The concentration of the carboxylic acid (hydrophilic) groups increase, and that of fluorocarbon (hydrophobic) groups decrease by lowering the duty cycle. The combined effect of surface chemistry and surface morphology of the RF pulsed plasma copolymer coatings causes tunable surface wettability and surface adhesion. The gradual emergence of hydrophilic contents leads to surface heterogeneity by lowering duty cycle causing an increased surface adhesion in hydrophobic coatings. The $\mathrm{C}_{4} \mathrm{~F}_{8}$-co-AA plasma polymer coatings on the nanotextured surfaces are tuned from repulsive superhydrophobicity to adhesive superhydrophobicity, and further to superhydrophilicity by adjusting the duty cycles with the monomer feed rates [115]. 


\section{Prominent Applications of Tunable Wettability and $\mathrm{pH}$-responsiveness}

As discussed above, tunable wettability and $\mathrm{pH}$-responsiveness have a variety of applications. In this section, an overview of some of these applications is presented.

\subsection{Oil-water Separation}

Removing oil from water is an essential industrial process and due to different affinities of water and oil, it is done by tuning surface wettability. This wettability based oil-water separation technique is highly effective and energy efficient as compared to conventional methods [116].

In this technique, a filter with selective wettability is used as a porous barrier that allows some components of permeation of selective wettability and rejects others. By polymer modification, many of these selective wettability filters with a pore size in micrometers range are fabricated. The function of these selective wettability filters is based on controlled wettability rather than size barrier. Mostly these selective wettability filters are superhydrophilic but oleophobic and vice versa $[117,118]$. The microfiltration polymer membranes with fixed wettability have also been used for a stabilized oil-water emulsion of micrometer oil droplet. These polymer membranes can efficiently separate both oil-in-water emulsions as well as immiscible oil-water mixtures, with high efficiency (rejection rate) above $99 \%[119,120]$. The polymers with stimuli-responsive wettability have also been used in selective wettability filters and membranes for oil-water separation as shown in Figure 12 [121].

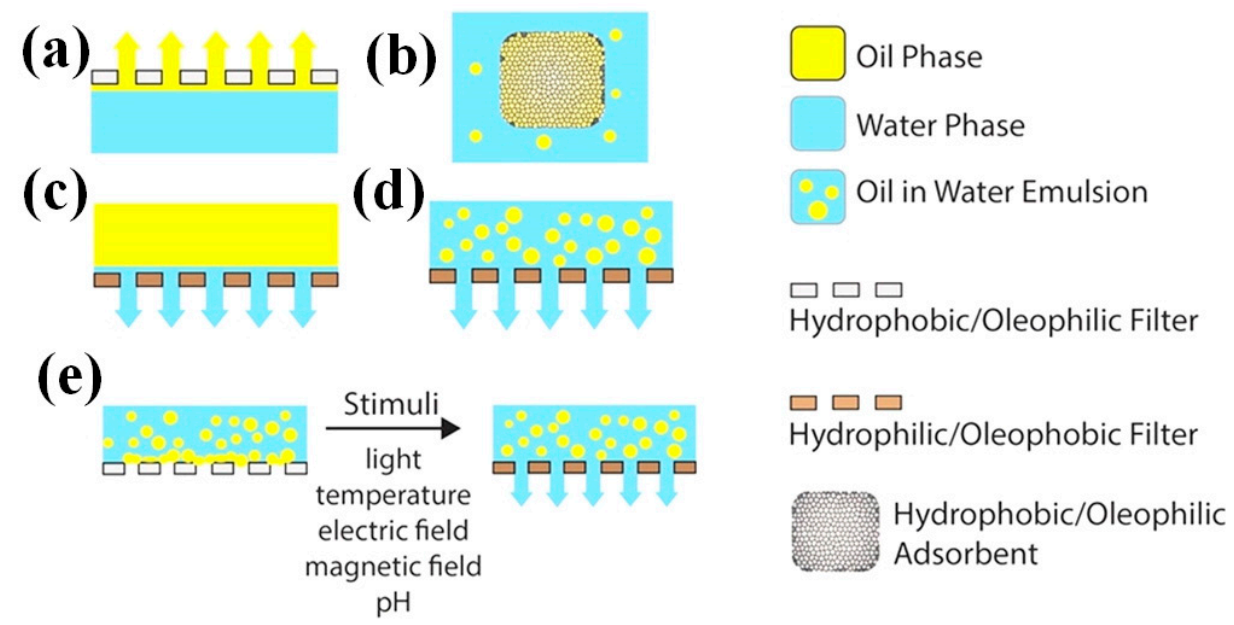

Figure 12. (a) Hydrophobic and oleophilic polymer filter for oil-water separation, (b) hydrophobic and oleophilic polymer sponge for oil absorbance from oil-in-water emulsion. (c) Hydrophilic and oleophobic polymer filter for oil-water separation, (d) hydrophilic and oleophobic polymer sponge for oil-in-water emulsion, (e) hydrophobic-oleophilic stimuli-responsive filter for oil-water separation [1].

\section{2. $p H$-responsive Tumor Targeted Drug Delivery}

The $\mathrm{pH}$-responsive biomaterials for tumor-targeted drug delivery have attracted much interest as $\mathrm{pH}$ in tumor tissue may be exploitable for selective targeting of tumors relative to normal tissues. The acidic $\mathrm{pH}($ low $\mathrm{pH})$ induced protonation causes the hydrophilic-hydrophobic transition. The carboxylic component is $\mathrm{pH}$-sensitive part of polymer deprotonated at physiological $\mathrm{pH}$ and shows hydrophilic state, while an acidic environment, due to the protonation polymer, becomes hydrophobic, leading to drug release. These $\mathrm{pH}$-responsive biomaterials in acidic environment accept protons and change their structure in three different ways to attained targeted drug release destabilization, precipitation or dissociation depending on the $\mathrm{pKa}$ value of a $\mathrm{pH}$-sensitive component of the polymer [122]. Polymers with carboxylic groups are commonly used for targeting the tumor tissue in the acidic environment [123]. At $7.4 \mathrm{pH}$, the carboxylic component is deprotonated and remains in the hydrophilic state. In an acidic environment, it is protonated and surface wettability 
changed to a hydrophobic state. The change in surface wettability leads to the deformation in the polymer, causing drug release [124].

\section{Conclusions}

The surfaces with tunable and stimuli-responsive switchable wettability are of great interest due to their promising applications. The plasma polymer surface modifiction method is describe in this review paper is aimed mostly to improve tunable wettability to improve biocompatibility to polymers. The copolymer, having hydrophobic and hydrophilic component, can be tuned to specific wettability by controlling monomer ratio, surface morphology and other deposition parameters. Moreover, many groups are claiming successful fabrication of copolymer surfaces with switchable wettability in response to external stimuli, such as $\mathrm{pH}$, light irradiation, temperature, chiral and counter ion. The most of the stimuli-responsive surfaces with switchable wettability typically show intrinsic responsive wettability due to the fixed functional responsive building block of copolymers. It is challenging to tune the chemical structures of responsive copolymers with controlled wetting/dewetting components due to the complicated procedures. This review has demonstrated recent advances to fabricate surfaces with tailored wettability by merely controlling plasma polymerization parameters. The controlled wettability can be used to design filters with selective wettability for oil-water separation industry. Moreover, this technique will be helpful to design the $\mathrm{pH}$-responsive biomaterials for tumor-targeted drug delivery. Polymers with tunable wettability may be another hotspot, which have great potentioal in the biomateril related field. This rich knowedge on surface wettability of plasma polymerized coatings will be benificial to biomadical applications.

Author Contributions: Conceptualization, M.I. (Muzammil Iqbal); formal analysis, M.I. (Muzammil Iqbal) and D.K.D.; investigation, M.I. (Muzammil Iqbal) and Q.A.; resources, M.I. (Muzammil Iqbal) and M.I. (Muhammad Imran); writing—original draft preparation, M.I. (Muzammil Iqbal) and H.S.; writing—review and editing, M.I. (Muzammil Iqbal) and A.U.A.

Funding: This research received no external funding.

Conflicts of Interest: The authors declare no conflict of interest.

\section{References}

1. Wang, Z.X.; Elimelech, M.; Lin, S.H. Environmental Applications of Interfacial Materials with Special Wettability. Environ. Sci. Technol. 2016, 50, 2132-2150. [CrossRef]

2. Falde, E.J.; Yohe, S.T.; Colson, Y.L.; Grinstaff, M.W. Superhydrophobic materials for biomedical applications. Biomaterials 2016, 104, 87-103. [CrossRef] [PubMed]

3. Siow, K.S.; Kumar, S.; Griesser, H.J. Low-Pressure Plasma Methods for Generating Non-Reactive Hydrophilic and Hydrogel-Like Bio-Interface Coatings-A Review. Plasma Process. Polym. 2015, 12, 8-24. [CrossRef]

4. Yao, X.; Song, Y.; Jiang, L. Applications of bio-inspired special wettable surfaces. Adv. Mater. 2011, 23, 719-734. [CrossRef] [PubMed]

5. Feng, L.; Li, S.; Li, Y.; Li, H.; Zhang, L.; Zhai, J.; Song, Y.; Liu, B.; Jiang, L.; Zhu, D. Super-hydrophobic surfaces: From natural to artificial. Adv. Mater. 2002, 14, 1857-1860. [CrossRef]

6. Khelifa, F.; Ershov, S.; Habibi, Y.; Snyders, R.; Dubois, P. Free-Radical-Induced Grafting from Plasma Polymer Surfaces. Chem. Rev. 2016, 116, 3975-4005. [CrossRef]

7. Denes, F. Macromolecular plasma-chemistry: An emerging field of polymer science. Prog. Polym. Sci. 2004, 29, 815-885. [CrossRef]

8. Odian, G. Principles of Polymerization; John Wiley \& Sons: Hoboken, NJ, USA, 2004.

9. Flory, P.J. Principles of Polymer Chemistry; Cornell University Press: Ithaca, NY, USA, 1953.

10. Ozaydin-Ince, G.; Coclite, A.M.; Gleason, K.K. CVD of polymeric thin films: Applications in sensors, biotechnology, microelectronics/organic electronics, microfluidics, MEMS, composites and membranes. Rep. Prog. Phys. Phys. Soc. 2012, 75, 016501. [CrossRef]

11. Sreenivasan, R.; Gleason, K.K. Overview of Strategies for the CVD of Organic Films and Functional Polymer Layers. Chem. Vap. Depos. 2009, 15, 77-90. [CrossRef] 
12. Friedrich, J. Mechanisms of Plasma Polymerization-Reviewed from a Chemical Point of View. Plasma Process. Polym. 2011, 8, 783-802. [CrossRef]

13. Bogaerts, A.; Neyts, E.; Gijbels, R.; van der Mullen, J. Gas discharge plasmas and their applications. Spectrochim. Acta Part B At. Spectrosc. 2002, 57, 609-658. [CrossRef]

14. Yasuda, H. Glow discharge polymerization. J. Polym. Sci. Macromol. Rev. 1981, 16, 199-293. [CrossRef]

15. Raizer, Y.P.; Shneider, M.N.; Yatsenko, N.A. Radio-Frequency Capacitive Discharges; CRC Press: Boca Raton, FL, USA, 1995.

16. Jérôme, P.; Jacques, S.; Christoph, H.; Alan, H.; Laurent, S. The physics of plasma-enhanced chemical vapour deposition for large-area coating: Industrial application to flat panel displays and solar cells. Plasma Phys. Control. Fusion 2000, 42, B353.

17. Inagaki, N. Plasma Surface Modification and Plasma Polymerization; CRC Press: Boca Raton, FL, USA, 2014.

18. Shen, M.; Bell, A.T. A Review of Recent Advances in Plasma Polymerization. Plasma Polym. 1979, 108, 1-33. [CrossRef]

19. Attri, P.; Arora, B.; Choi, E.H. Utility of plasma: A new road from physics to chemistry. RSC Adv. 2013, 3, 12540. [CrossRef]

20. Michelmore, A.; Steele, D.A.; Whittle, J.D.; Bradley, J.W.; Short, R.D. Nanoscale deposition of chemically functionalised films via plasma polymerisation. RSC Adv. 2013, 3, 13540. [CrossRef]

21. Förch, R.; Zhang, Z.; Knoll, W. Soft Plasma Treated Surfaces: Tailoring of Structure and Properties for Biomaterial Applications. Plasma Process. Polym. 2005, 2, 351-372. [CrossRef]

22. Friedrich, J. Pulsed-Plasma Polymerization. In The Plasma Chemistry of Polymer Surfaces; Wiley-VCH Verlag GmbH \& Co. KGaA: Weinheim, Germany, 2012; Chapter 12; pp. 377-456.

23. Yasuda, H.; Hsu, T. Some aspects of plasma polymerization investigated by pulsed RF discharge. J. Polym. Sci. Part A Polym. Chem. 1977, 15, 81-97. [CrossRef]

24. Swaraj, S.; Oran, U.; Friedrich, J.F.; Lippitz, A.; Unger, W.E.S. Surface Chemical Analysis of Plasma-Deposited Copolymer Films Prepared from Feed Gas Mixtures of Ethylene or Styrene with Allyl Alcohol. Plasma Process. Polym. 2007, 4, 376-389. [CrossRef]

25. Elias, H.-G. Macromolecules: Volume 2: Synthesis, Materials, and Technology; Springer: New York, NY, USA, 2013.

26. Förster, S.; Antonietti, M. Amphiphilic Block Copolymers in Structure-Controlled Nanomaterial Hybrids. Adv. Mater. 1998, 10, 195-217. [CrossRef]

27. Feng, X.J.; Jiang, L. Design and Creation of Superwetting/Antiwetting Surfaces. Adv. Mater. 2006, 18, 3063-3078. [CrossRef]

28. Liu, K.S.; Tian, Y.; Jiang, L. Bio-inspired superoleophobic and smart materials: Design, fabrication, and application. Prog. Mater Sci. 2013, 58, 503-564. [CrossRef]

29. Nimittrakoolchai, O.U.; Supothina, S. Deposition of organic-based superhydrophobic films for anti-adhesion and self-cleaning applications. J. Eur. Ceram. Soc. 2008, 28, 947-952. [CrossRef]

30. Good, R.J. Contact angle, wetting, and adhesion: A critical review. J. Adhes. Sci. Technol. 1992, 6, $1269-1302$. [CrossRef]

31. Valipour, M.N.; Birjandi, F.C.; Sargolzaei, J. Super-non-wettable surfaces: A review. Colloids Surf. A Physicochem. Eng. Asp. 2014, 448, 93-106. [CrossRef]

32. Hsieh, C.T.; Wu, F.L.; Chen, W.Y. Super water- and oil-repellencies from silica-based nanocoatings. Surf. Coat. Technol. 2009, 203, 3377-3384. [CrossRef]

33. Liu, M.J.; Zheng, Y.M.; Zhai, J.; Jiang, L. Bioinspired Super-antiwetting Interfaces with Special Liquid-Solid Adhesion. Acc. Chem. Res. 2010, 43, 368-377. [CrossRef] [PubMed]

34. Liu, M.J.; Wang, S.T.; Wei, Z.X.; Song, Y.L.; Jiang, L. Bioinspired Design of a Superoleophobic and Low Adhesive Water/Solid Interface. Adv. Mater. 2009, 21, 665-669. [CrossRef]

35. Extrand, C.W. Water contact angles and hysteresis of polyamide surfaces. J. Colloid Interface Sci. 2002, 248, 136-142. [CrossRef]

36. Quéré, D. Wetting and Roughness. Annu. Rev. Mater. Res. 2008, 38, 71-99. [CrossRef]

37. Wenzel, R.N. Resistance of solid surfaces to wetting by water. Ind. Eng. Chem. 1936, 28, 988-994. [CrossRef]

38. Cassie, A.B.D.; Baxter, S. Wettability of porous surfaces. Trans. Faraday Soc. 1944, 40, 546-551. [CrossRef]

39. Marmur, A. Solid-Surface Characterization by Wetting. Annu. Rev. Mater. Res. 2009, 39, 473-489. [CrossRef]

40. Hsieh, C.T.; Chen, J.M.; Kuo, R.R.; Lin, T.S.; Wu, C.F. Influence of surface roughness on water- and oil-repellent surfaces coated with nanoparticles. Appl. Surf. Sci. 2005, 240, 318-326. [CrossRef] 
41. Fernandez, A.; Francone, A.; Thamdrup, L.H.; Johanson, A.; Bilenberg, B.; Nielsen, T.; Guttmann, M.; Torres, C.M.S.; Kehagias, N. Design of Hierarchical Surfaces for Tuning Wetting Characteristics. ACS Appl. Mater. Interfaces 2017, 9, 7701-7709. [CrossRef]

42. Nosonovsky, M.; Bhushan, B. Hierarchical roughness optimization for biomimetic superhydrophobic surfaces. Ultramicroscopy 2007, 107, 969-979. [CrossRef]

43. Bico, J.; Thiele, U.; Quéré, D. Wetting of textured surfaces. Colloids Surf. A Physicochem. Eng. Asp. 2002, 206, 41-46. [CrossRef]

44. Jai, C.; Ferencz, S.D.; Richard, B.T. Plasma Processing Approach to Molecular Surface Tailoring of Nanoparticles: Improved Photocatalytic Activity of $\mathrm{TiO}_{2}$. Chem. Mater. 2006, 18, 2989-2996. [CrossRef]

45. Friedrich, J. The Plasma Chemistry of Polymer Surfaces: Advanced Techniques for Surface Design; Wiley Online Library: Hoboken, NJ, USA, 2012.

46. Kropewnicki, T.J.; Pender, J.T.; Fong, H.; Auglis, C.P.; Hung, R.; Shan, H. Substrate Cleaning Process. Google Patents US6440864B1, 27 August 2002.

47. Liston, E.M. Plasma treatment for improved bonding: A review. J. Adhes. 1989, 30, 199-218. [CrossRef]

48. Sardella, E.; Favia, P.; Gristina, R.; Nardulli, M.; d'Agostino, R. Plasma-Aided Micro-and Nanopatterning Processes for Biomedical Applications. Plasma Process. Polym. 2006, 3, 456-469. [CrossRef]

49. Alenka, V.; Miran, M. New developments in surface functionalization of polymers using controlled plasma treatments. J. Phys. D Appl. Phys. 2017, 50, 293001.

50. Liston, E.M.; Martinu, L.; Wertheimer, M.R. Plasma surface modification of polymers for improved adhesion: A critical review. J. Adhes. Sci. Technol. 1993, 7, 1091-1127. [CrossRef]

51. Guruvenket, S.; Rao, G.M.; Komath, M.; Raichur, A.M. Plasma surface modification of polystyrene and polyethylene. Appl. Surf. Sci. 2004, 236, 278-284. [CrossRef]

52. Truica-Marasescu, F.; Wertheimer, M.R. Nitrogen-Rich Plasma-Polymer Films for Biomedical Applications. Plasma Process. Polym. 2008, 5, 44-57. [CrossRef]

53. Schröder, K.; Meyer-Plath, A.; Keller, D.; Besch, W.; Babucke, G.; Ohl, A. Plasma-Induced Surface Functionalization of Polymeric Biomaterials in Ammonia Plasma. Contrib. Plasma Phys. 2001, 41, 562-572. [CrossRef]

54. Boeda, J.C.; de Mendez, M.; Legeay, G.; Brosse, J.C. Use of low temperature plasmas for polymer surface treatments. Rev. Gen. Electr. (Fr.) 1987, 5, 15-21.

55. Chen, J.-K.; Lin, I.K.; Ko, F.-H.; Huang, C.-F.; Chen, K.-S.; Chan, C.-H.; Chang, F.-C. Behavior and surface energies of polybenzoxazines formed by polymerization with argon, oxygen, and hydrogen plasmas. J. Polym. Sci. Part B Polym. Phys. 2004, 42, 4063-4074. [CrossRef]

56. Kim, B.K.; Kim, K.S.; Park, C.E.; Ryu, C.M. Improvement of wettability and reduction of aging effect by plasma treatment of low-density polyethylene with argon and oxygen mixtures. J. Adhes. Sci. Technol. 2002, 16, 509-521. [CrossRef]

57. Ting, Y.H.; Liu, C.C.; Park, S.M.; Jiang, H.Q.; Nealey, P.F.; Wendt, A.E. Surface Roughening of Polystyrene and Poly(methyl methacrylate) in Ar/O-2 Plasma Etching. Polymers 2010, 2, 649-663. [CrossRef]

58. Chan, C.M.; Ko, T.M.; Hiraoka, H. Polymer surface modification by plasmas and photons. Surf. Sci. Rep. 1996, 24, 1-54. [CrossRef]

59. Ho, C.-P.; Yasuda, H. Ultrathin coating of plasma polymer of methane applied on the surface of silicone contact lenses. J. Biomed. Mater. Res. 1988, 22, 919-937. [CrossRef]

60. Yamagishi, F.G.; Granger, D.D.; Schmitz, A.E.; Miller, L.A. Plasma-polymerized films as moisture barriers for alkali halide optics. Thin Solid Films. 1981, 84, 427-434. [CrossRef]

61. Lau, K.K.S.; Bico, J.; Teo, K.B.K.; Chhowalla, M.; Amaratunga, G.A.J.; Milne, W.I.; McKinley, G.H.; Gleason, K.K. Superhydrophobic Carbon Nanotube Forests. Nano Lett. 2003, 3, 1701-1705. [CrossRef]

62. Coulson, S.R.; Woodward, I.S.; Badyal, J.P.S.; Brewer, S.A.; Willis, C. Ultralow surface energy plasma polymer films. Chem. Mater. 2000, 12, 2031-2038. [CrossRef]

63. Teare, D.O.H.; Spanos, C.G.; Ridley, P.; Kinmond, E.J.; Roucoules, V.; Badyal, J.P.S.; Brewer, S.A.; Coulson, S.; Willis, C. Pulsed Plasma Deposition of Super-Hydrophobic Nanospheres. Chem. Mater. 2002, 14, 4566-4571. [CrossRef]

64. Hasirci, N. Silicone polymerization by glow discharge application. J. Appl. Polym. Sci. 1987, 34, 1135-1144. [CrossRef] 
65. Hasirci, N. Surface modification of charcoal by glow-discharge: The effect on blood cells. J. Appl. Polym. Sci. 1987, 34, 2457-2468. [CrossRef]

66. Bieg, K.W.; Wischmann, K.B. Plasma-polymerized organosilanes as protective coatings for solar front-surface mirrors. Sol. Energy Mater. 1980, 3, 301-316. [CrossRef]

67. Inagaki, N.; Hirao, H. Plasma polymers containing sulfonate groups. J. Polym. Sci. Part A Polym. Chem. 1987, 25, 1803-1809. [CrossRef]

68. Inagaki, N.; Tasaka, S.; Yamada, Y. Plasma polymerization of cyano compounds. J. Polym. Sci. Part A Polym. Chem. 1992, 30, 2003-2010. [CrossRef]

69. Hirotsu, T. Cyano and Analogous Groups in Plasma Polymers from Nitrogen Monomers. J. Macromol. Sci. Part A-Chem. 1981, 15, 633-641. [CrossRef]

70. Inagaki, N.; Oh-Ishi, K. Preparation of amino group-containing polymers by plasma polymerization. J. Polym. Sci. Polym. Chem. Ed. 1985, 23, 1445-1454. [CrossRef]

71. Mangindaan, D.; Kuo, W.-H.; Chang, C.-C.; Wang, S.-L.; Liu, H.-C.; Wang, M.-J. Plasma polymerization of amine-containing thin films and the studies on the deposition kinetics. Surf. Coat. Technol. 2011, 206, 1299-1306. [CrossRef]

72. Gancarz, I.; Poźniak, G.; Bryjak, M.; Tylus, W. Modification of polysulfone membranes 5. Effect of n-butylamine and allylamine plasma. Eur. Polym. J. 2002, 38, 1937-1946. [CrossRef]

73. Swaraj, S.; Oran, U.; Lippitz, A.; Unger, W.E.S. Surface Chemical Analysis of Plasma-Deposited Copolymer Films Prepared from Feed Gas Mixtures of Ethylene or Styrene with Allylamine. Plasma Process. Polym. 2008, 5, 92-104. [CrossRef]

74. Golub, M.A.; Wydeven, T.; Cormia, R.D. Plasma copolymerization of ethylene and tetrafluoroethylene. J. Polym. Sci. Part A Polym. Chem. 1992, 30, 2683-2692. [CrossRef]

75. Leezenberg, P.B.; Reiley, T.C.; Tyndall, G.W. Plasma induced copolymerization of hexafluoropropylene and octafluoropropane. J. Vac. Sci. Technol. A 1999, 17, 275-281. [CrossRef]

76. Jiang, H.; Eyink, K.; Grant, J.T.; Enlow, J.; Tullis, S.; Bunning, T.J. PECVD Siloxane and Fluorine-Based Copolymer Thin Films. Chem. Vap. Depos. 2008, 14, 286-291. [CrossRef]

77. Beck, A.J.; Jones, F.R.; Short, R.D. Plasma copolymerization as a route to the fabrication of new surfaces with controlled amounts of specific chemical functionality. Polymer 1996, 37, 5537-5539. [CrossRef]

78. Beck, A.J.; Whittle, J.D.; Bullett, N.A.; Eves, P.; Mac Neil, S.; McArthur, S.L.; Shard, A.G. Plasma co-polymerisation of two strongly interacting monomers: Acrylic acid and allylamine. Plasma Process. Polym. 2005, 2, 641-649. [CrossRef]

79. Hirotsu, T.; Tagaki, C.; Partridge, A. Plasma Copolymerization of Acrylic Acid with Hexamethyldisilazane. Plasmas Polym. 2002, 7, 353-366. [CrossRef]

80. Fahmy, A.; Mix, R.; Schönhals, A.; Friedrich, J. Structure of Plasma-Deposited Copolymer Films Prepared from Acrylic Acid and Styrene: Part I Dependence on the Duty Cycle. Plasma Process. Polym. 2012, 9, 273-284. [CrossRef]

81. Fahmy, A.; Mix, R.; Schönhals, A.; Friedrich, J. Structure of Plasma-Deposited Copolymer Films Prepared from Acrylic Acid and Styrene: Part II Variation of the Comonomer Ratio. Plasma Process. Polym. 2013, 10, 750-760. [CrossRef]

82. Chahine, C.; Poncin-Epaillard, F.; Debarnot, D. Plasma Copolymerization of Fluorinated and Acrylate Monomers: Kinetics and Chemical Structure Study. Plasma Process. Polym. 2014. [CrossRef]

83. Lafuma, A.; Quere, D. Superhydrophobic states. Nat. Mater. 2003, 2, 457-460. [CrossRef] [PubMed]

84. Ma, M.; Hill, R.M. Superhydrophobic surfaces. Curr. Opin. Colloid Interface Sci. 2006, 11, 193-202. [CrossRef]

85. Kay, E.; Dilks, A. Plasma polymerization of fluorocarbons in rf capacitively coupled diode system. J. Vac. Sci. Technol. 1981, 18, 1-11. [CrossRef]

86. Yasuda, H.; Hsu, T.S. Some aspects of plasma polymerization of fluorine-containing organic compounds. J. Polym. Sci. Polym. Chem. Ed. 1977, 15, 2411-2425. [CrossRef]

87. Lee, J.; Kim, K.-J.; Lee, Y. Characterization of fluorocarbon thin films deposited by ICP and PP. J. Surf. Anal. 2011, 17, 269-273. [CrossRef]

88. Furuya, K.; Nakanishi, R.; Okumura, H.; Makita, M.; Harata, A. Influence of substrate type on surface structure of polymeric perfluorocarbon in the initial stage of deposition in Ar/c-C4F8 plasmas. Thin Solid Films 2008, 516, 6028-6032. [CrossRef] 
89. Di Mundo, R.; De Benedictis, V.; Palumbo, F.; d'Agostino, R. Fluorocarbon plasmas for nanotexturing of polymers: A route to water-repellent antireflective surfaces. Appl. Surf. Sci. 2009, 255, 5461-5465. [CrossRef]

90. Tsougeni, K.; Vourdas, N.; Tserepi, A.; Gogolides, E.; Cardinaud, C. Mechanisms of oxygen plasma nanotexturing of organic polymer surfaces: From stable super hydrophilic to super hydrophobic surfaces. Langmuir ACS J. Surf. Colloids 2009, 25, 11748-11759. [CrossRef]

91. Martin, I.T.; Malkov, G.S.; Butoi, C.I.; Fisher, E.R. Comparison of pulsed and downstream deposition of fluorocarbon materials from $\mathrm{C}_{3} \mathrm{~F}_{8}$ and $\mathrm{c}-\mathrm{C}_{4} \mathrm{~F}_{8}$ plasmas. J. Vac. Sci. Technol. A Vac. Surf. Films 2004, 22, 227. [CrossRef]

92. Labelle, C.B.; Opila, R.; Kornblit, A. Plasma deposition of fluorocarbon thin films from c- $\mathrm{C}_{4} \mathrm{~F}_{8}$ using pulsed and continuous rf excitation. J. Vac. Sci. Technol. A Vac. Surf. Films 2005, 23, 190. [CrossRef]

93. Labelle, C.B.; Gleason, K.K. Pulsed plasma-enhanced chemical vapor deposition from $\mathrm{CH}_{2} \mathrm{~F}_{2}, \mathrm{C}_{2} \mathrm{H}_{2} \mathrm{~F}_{4}$, and $\mathrm{CHClF}_{2}$. J. Vac. Sci. Technol. A Vac. Surf. Films 1999, 17, 445. [CrossRef]

94. Labelle, C.B.; Limb, S.J.; Gleason, K.K. Electron spin resonance of pulsed plasma-enhanced chemical vapor deposited fluorocarbon films. J. Appl. Phys. 1997, 82, 1784. [CrossRef]

95. Träubel, H. Hydrophilic Polymers. In New Materials Permeable to Water Vapor; Springer: Berlin/Heidelberg, Germany, 1999; pp. 133-152.

96. Lai, J.; Sunderland, B.; Xue, J.; Yan, S.; Zhao, W.; Folkard, M.; Michael, B.D.; Wang, Y. Study on hydrophilicity of polymer surfaces improved by plasma treatment. Appl. Surf. Sci. 2006, 252, 3375-3379. [CrossRef]

97. Akkan, C.K.; Hammadeh, M.; Brück, S.; Park, H.W.; Veith, M.; Abdul-Khaliq, H.; Aktas, C. Plasma and short pulse laser treatment of medical grade PEEK surfaces for controlled wetting. Mater. Lett. 2013, 109, 261-264. [CrossRef]

98. Hatakeyama, H.; Hatakeyama, T. Interaction between water and hydrophilic polymers. Thermochim. Acta 1998, 308, 3-22. [CrossRef]

99. Finch, C.A. Hydrophilic polymers. In Specialty Polymers; Dyson, R.W., Ed.; Springer: Boston, MA, USA, 1987; pp. 65-82.

100. Allméar, K.; Hult, A.; Rårnby, B. Surface modification of polymers. I. Vapour phase photografting with acrylic acid. J. Polym. Sci. Part A Polym. Chem. 1988, 26, 2099-2111. [CrossRef]

101. Gupta, B.; Plummer, C.; Bisson, I.; Frey, P.; Hilborn, J. Plasma-induced graft polymerization of acrylic acid onto poly(ethylene terephthalate) films: Characterization and human smooth muscle cell growth on grafted films. Biomaterials 2002, 23, 863-871. [CrossRef]

102. Sciarratta, V.; Vohrer, U.; Hegemann, D.; Müller, M.; Oehr, C. Plasma functionalization of polypropylene with acrylic acid. Surf. Coat. Technol. 2003, 174-175, 805-810. [CrossRef]

103. Jafari, R.; Tatoulian, M.; Morscheidt, W.; Arefi-Khonsari, F. Stable plasma polymerized acrylic acid coating deposited on polyethylene (PE) films in a low frequency discharge (70 kHz). React. Funct. Polym. 2006, 66, 1757-1765. [CrossRef]

104. Voronin, S.A.; Bradley, J.W.; Fotea, C.; Zelzer, M.; Alexander, M.R. Characterization of thin-film deposition in a pulsed acrylic acid polymerizing discharge. J. Vac. Sci. Technol. A Vac. Surf. Films 2007, 25, 1093. [CrossRef]

105. Fahmy, A.; Mix, R.; Schönhals, A.; Friedrich, J.F. Structure of Plasma-Deposited Poly(acrylic acid) Films. Plasma Process. Polym. 2011. [CrossRef]

106. Peter, N.J.; Zhang, X.-S.; Chu, S.-G.; Zhu, F.-Y.; Seidel, H.; Zhang, H.-X. Tunable wetting behavior of nanostructured poly(dimethylsiloxane) by plasma combination treatments. Appl. Phys. Lett. 2012, 101, 221601. [CrossRef]

107. Yilgor, I.; Bilgin, S.; Isik, M.; Yilgor, E. Tunable wetting of polymer surfaces. Langmuir ACS J. Surf. Colloids 2012, 28, 14808-14814. [CrossRef]

108. Guo, F.; Guo, Z. Inspired smart materials with external stimuli responsive wettability: A review. RSC Adv. 2016, 6, 36623-36641. [CrossRef]

109. Zhang, Q.; Xia, F.; Sun, T.; Song, W.; Zhao, T.; Liu, M.; Jiang, L. Wettability switching between high hydrophilicity at low $\mathrm{pH}$ and high hydrophobicity at high $\mathrm{pH}$ on surface based on $\mathrm{pH}$-responsive polymer. Chem. Commun. 2008, 1199-1201. [CrossRef] [PubMed]

110. Xu, C.; Wayland, B.B.; Fryd, M.; Winey, K.I.; Composto, R.J. pH-responsive nanostructures assembled from amphiphilic block copolymers. Macromolecules 2006, 39, 6063-6070. [CrossRef]

111. Zhou, Y.N.; Li, J.J.; Luo, Z.H. Toward Efficient Water/Oil Separation Material: Effect of Copolymer Composition on pH-Responsive Wettability and Separation Performance. Aiche J. 2016, 62, 1758-1771. [CrossRef] 
112. Xia, F.; Feng, L.; Wang, S.; Sun, T.; Song, W.; Jiang, W.; Jiang, L. Dual-Responsive Surfaces That Switch between Superhydrophilicity and Superhydrophobicity. Adv. Mater. 2006, 18, 432-436. [CrossRef]

113. Muzammil, I.; Li, Y.; Lei, M. Tunable wettability and $\mathrm{pH}$-responsiveness of plasma copolymers of acrylic acid and octafluorocyclobutane. Plasma Process. Polym. 2017, 14, 1700053. [CrossRef]

114. Muzammil, I.; Li, Y.; Lei, M. Cover Picture: Multifunctional Smart Polymer Coatings 10/2017. Plasma Process. Polym. 2017, 14, 1770019. [CrossRef]

115. Muzammil, I.; Li, Y.P.; Li, X.Y.; Lei, M.K. Duty cycle dependent chemical structure and wettability of RF pulsed plasma copolymers of acrylic acid and octafluorocyclobutane. Appl. Surf. Sci. 2018, 436, 411-418. [CrossRef]

116. Xue, Z.; Cao, Y.; Liu, N.; Feng, L.; Jiang, L. Special wettable materials for oil/water separation. J. Mater. Chem. A 2014, 2, 2445-2460. [CrossRef]

117. Wang, B.; Li, J.; Wang, G.; Liang, W.; Zhang, Y.; Shi, L.; Guo, Z.; Liu, W. Methodology for Robust Superhydrophobic Fabrics and Sponges from In Situ Growth of Transition Metal/Metal Oxide Nanocrystals with Thiol Modification and Their Applications in Oil/Water Separation. ACS Appl. Mater. Interfaces 2013, 5, 1827-1839. [CrossRef] [PubMed]

118. Zhang, J.; Seeger, S. Polyester Materials with Superwetting Silicone Nanofilaments for Oil/Water Separation and Selective Oil Absorption. Adv. Funct. Mater. 2011, 21, 4699-4704. [CrossRef]

119. Kwon, G.; Kota, A.K.; Li, Y.; Sohani, A.; Mabry, J.M.; Tuteja, A. On-Demand Separation of Oil-Water Mixtures. Adv. Mater. 2012, 24, 3666-3671. [CrossRef] [PubMed]

120. Xue, Z.; Wang, S.; Lin, L.; Chen, L.; Liu, M.; Feng, L.; Jiang, L. A Novel Superhydrophilic and Underwater Superoleophobic Hydrogel-Coated Mesh for Oil/Water Separation. Adv. Mater. 2011, 23, 4270-4273. [CrossRef]

121. Wang, B.; Guo, Z. pH-responsive bidirectional oil-water separation material. Chem. Commun. 2013, 49, 9416-9418. [CrossRef] [PubMed]

122. Deng, H.; Liu, J.; Zhao, X.; Zhang, Y.; Liu, J.; Xu, S.; Deng, L.; Dong, A.; Zhang, J. PEG-b-PCL Copolymer Micelles with the Ability of $\mathrm{pH}$-Controlled Negative-to-Positive Charge Reversal for Intracellular Delivery of Doxorubicin. Biomacromolecules 2014, 15, 4281-4292. [CrossRef] [PubMed]

123. Kang, X.-J.; Dai, Y.-L.; Ma, P.-A.; Yang, D.-M.; Li, C.-X.; Hou, Z.-Y.; Cheng, Z.-Y.; Lin, J. Poly(acrylic acid)-Modified $\mathrm{Fe}_{3} \mathrm{O}_{4}$ Microspheres for Magnetic-Targeted and $\mathrm{pH}$-Triggered Anticancer Drug Delivery. Chem. A Eur. J. 2012, 18, 15676-15682. [CrossRef]

124. Ding, D.; Wang, J.; Zhu, Z.; Li, R.; Wu, W.; Liu, B.; Jiang, X. Tumor Accumulation, Penetration, and Antitumor Response of Cisplatin-Loaded Gelatin/Poly(acrylic acid) Nanoparticles. ACS Appl. Mater. Interfaces 2012, 4, 1838-1846. [CrossRef] [PubMed]

(C) 2019 by the authors. Licensee MDPI, Basel, Switzerland. This article is an open access article distributed under the terms and conditions of the Creative Commons Attribution (CC BY) license (http://creativecommons.org/licenses/by/4.0/). 